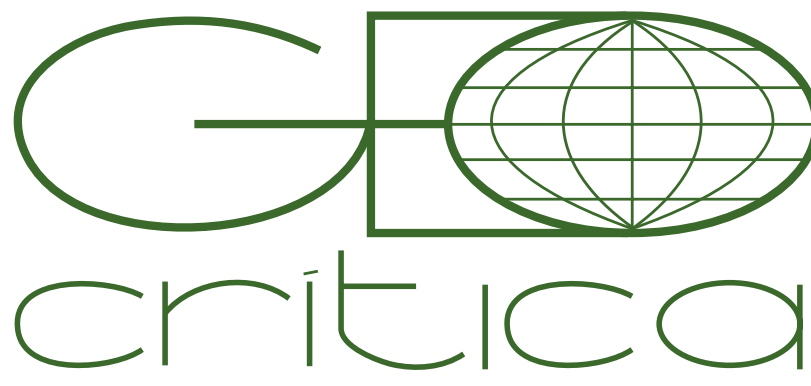

\section{Scripta Nova}

Revista Electrónica de Geografía y Ciencias Sociales Universitat de Barcelona

15 de marzo de 2019

\title{
CRISI, DESIGUALTAT I ANÀLISI ECONÒMICA, 1910-2015: ALGUNS INSTRUMENTS DE L'ECONOMIA CLÀSSICA
}

\author{
Carles Manera \\ carles.manera@uib.es \\ Universitat de les Illes Balears \\ Ferran Navinés \\ fnavines@gmail.com \\ Universitat de les Illes Balears \\ Javier Franconetti \\ jfranconetti@economistas.org \\ Universitat de les Illes Balears \\ José Pérez Montiel \\ joseperezmontiel@yahoo.es \\ Universitat de les Illes Balears \\ Rebut 2 març 2018 / Retornat per correccions 2 juliol 2018 / Acceptat 24 setembre 2018
}

Aquest treball fa part del projecte d'investigació "Crisis industrial y recuperación productiva en la historia de España, 1686-2018", HAR201564769-P., dirigit per Jordi Catalan. Hom agraeix I'ajuda del Ministerio de Economía y Competitividad. També volem agrair els comentaris de gran utilitat dels referees d'aquest treball.
Crisi, desigualtat i anàlisi econòmica, 1910-2015: alguns instruments de l'economia clàssica (Resum)

El treball es focalitza sobre la interpretació de la Gran Recessió a partir d'alguns dels postulats provinents de l'economia clàssica i, en concret, de les teories de D. Ricardo, K. Marx i el complement de J.A. Schumpeter. Hom defensa la importància d'analitzar la crisi a partir d'indicadors que, generalment, es tenen poc en consideració per part de l'economia convencional: la naturalesa endògena de les crisis, l'evolució de la taxa de benefici i l'observació de la tendència a la productivitat del capital.

Paraules clau: Gran Recessió, desigualtat, economia nordamericana, taxa de benefici, productivitat del capital, teoria de regulació, Ricardo, Marx, Schumpeter.

Crisis, inequality and economic analysis, 1910-2015: some economic classical instrumentss (Abstract)

The work focuses on the interpretation of the Great Recession from some assumptions from classical economics and, in particular, the theories of D. Ricardo, K. Marx and complement J.A. Schumpeter. It defends the importance of analyzing the crisis based on indicators that are generally considered to have little of conventional economics: the endogenous nature of the crisis, the evolution of the rate of profit and observation the trend in capital productivity.

Keywords: Great Recession, inequality, american economics, rate of profit, capital productivity, regulation's theory, Ricardo, Marx, Schumpeter. 
L'economia com a disciplina científica es troba en un terreny veritablement difícil. S'ha revelat, de manera crua, la seva incapacitat absoluta per fer allò que, d'alguna forma, els diferents mainstream existents al llarg de la recent història del pensament econòmic havien dit: la disponibilitat tangible a predir les tendències del futur, a partir de modelitzacions matemàtiques que facilitaven dits auguris. En aquest context, els economistes convencionals s'han trobat atrapats pels seus discursos litúrgics i teològics, que han esdevingut en posicionaments i diagnosis més vinculades a la fe que a la demostració científica. Les veus discordants amb tot això són cada vegada més nombroses, ${ }^{1}$ tot i que no es veuen avalades pels acadèmics del mainstream: aquests continuen perllongant, en plans d'estudi i programes de recerca, les velles receptes fallides, els discursos i manuals que s'han revelat, massa sovint, inútils per a fer front als grans reptes de l'economia i de la societat. Continuem ensenyant als estudiants d'Econòmiques els mateixos textos -adobats amb nou instrumental economètric, això sí- que flueixen dels poderosos Journals i editorials que marquen la doctrina: que determinen com i què ensenyar, estudiar i analitzar en el món econòmic. I sempre per aquest ordre.

El treball que es presenta té una doble finalitat. Per un costat, es recullen dues reflexions metodològiques a tall de presentació d'un determinat grup de teories econòmiques que es circumscriuen dins l'àmbit de l'Economia Política, i que, per tant, no formen part del corpus teòric convencional, les quals considerem bàsiques per a l'anàlisi de les crisis del capitalisme. I, per l'altre, presentem una anàlisi aplicada a partir del corpus teòric exposat en els dos apartats anteriors. Pel que fa a les acotacions teòriques, l'exposició s'ha ordenat de la següent manera. Un primer apartat tracta sobre l'aportació de K. Marx i la connexió interpretativa amb el cicle productiu industrial decennal -amb fortes influències ricardianes, derivades dels rendiments decreixents-, a partir de les anotacions de P. Sylos Labini. ${ }^{2}$ K. Marx també fa referència als cicles d'ona llarga i a les crisis sistèmiques del capitalisme; i aquí la nostra aportació entronca amb la Teoria de la Regulació i, més concretament, la formulació que en fa G. De Bernis, amb la reinterpretació del concepte sobre regulació capitalista per un costat, i per l'altre, amb la recuperació de la idea sobre la tendència a la igualació de la taxa de guany (TITG). ${ }^{3}$ Un segon apartat es vincula -amb fortes relacions amb el precedent- amb J. A. Schumpeter i el plantejament de les innovacions a les estructures econòmiques i les crisis d'ona llarga provocades per la

1 A tall d'exemple, Lapavitsas 2009, 2013; De Grauwe, "Governance of a Fragile Eurozone», Economic Policy, CEPS working documents, http://www.ceps.eu/book/governance-fragile-eurozone, 2011; Tapia-Astarita 2011; Keen 2013; Flassbeck et alter 2013; Varoufakis-Holland-Galbraith, http:// varoufakis.files.wordpress.com/2013/07/a-modest-proposal-for-resolving-the-eurozone-crisis-

version-4-0-finall.pdf, 2013; Lapavitsas- Flassbeck 2015. Les aportacions de M. Hudson han resultat alliçonadores des d'un punt de vista teòric; vegeu Finance Capitalism and its Discontents. Interviews and speeches, 2003-2012, Dresden, ISLET, 2012.

2 Ricardo 2003; Marx 2010; Sylos Labini 1988.

3 De Bernis 1988; i sobretot, Actualidad de G. D. De Bernis, 2013, inèdit. Agraim al professor J.M. Bricall la proporció d'aquest text. L'argumentació original de la TITG es troba ja a les aportacions dels economistes clàssics. 
irrupció de les revolucions tecnològiques; en aquest punt, incorporem les idees de H. Minsky i C. Pérez, que entronquen directament amb l'escola evolucionista. ${ }^{4}$

Pel que fa a l'anàlisi aplicada, es presenta en un tercer apartat, en el què s'aborden les següents qüestions clau:

a) L'anàlisi de la periodificació capitalista i els modes de regulació en les fases en què el sistema capitalista pot funcionar de forma regulada, anàlisi que realitzem a partir de la definició dels valors de la quota d'excedent (pes de l'excedent brut d'explotació en l'ingrés nacional, $\left.q=\frac{\mathrm{EBE}}{\mathrm{Y}}\right)$ d'equilibri, identificats com $\left(\mathrm{q}^{*}\right)$, quan aquells es troben situats dins de la forquilla d'equilibri de $(\mathrm{q})$. Fora de la forma regulada es poden caracteritzar dos tipus de crisis de regulació: les de demanda, és a dir, les provocades perquè els valors de q són superiors que q* com s'observà a la Gran Depressió de 1929 i la Gran Recessió iniciada el 2008; o les crisis de costos de producción excessius, quan els valors de q es troben per sota de q*, que també acaben derivant en una crisi de demanda, que és la que es va bastir al llarg del període 1968-1980.

b) L'anàlisi de les crisis de regulació o grans crisis del capitalisme, a partir de la caiguda disruptiva de la taxa de guany, per tal de poder diferenciar dos factors:

- que una crisi de regulació doni pas a un canvi, per la qual cosa fa falta que la caiguda de la taxa de guany ( $r$ ) sigui molt significativa, com va passar amb la crisi dels anys 1970, que va provocar el canvi de la regulació keynesiana per la neoliberal des de 1980;

- que no es produeixi aquesta caiguda disruptiva de la taxa de guany, com ha passat amb la Gran Recessió i, per tant, no s'ha produït encara la necessitat de canviar la regulació neoliberal per una altra.

c) L'anàlisi del procés de regulació capitalista a partir de les variables explicatives de la taxa de guany, que són:

- la productivitat del capital $(\pi \mathrm{k})$,

- la quota d'excedent (q),

- la taxa de financiarització de l'economia $(\alpha)$.

d) L'anàlisi del procés de destrucció creadora del capitalisme o procés definit per la competencia de capitals, el qual determina cap a on s'inverteixen els excedents generats per l'economia, en funció de les diferents rendibilitats que mostren les empreses no financeres en relació a la que puguin mantenir les empreses i els mercats financers.

El text clou amb unes reflexions finals, que recullen les primordials idees força comentades. El repàs a dit ideari s'encabeix en el fonament empíric de la recerca que estam duent a terme sobre l'economia nord-americana i les principals economies

4 Minsky 2008a, 2008b; Pérez 2004; Schumpeter 2002, 2012. 
europees, amb unes coordenades cronològiques que abasten, segons els casos, el període 1910-2010. En aquest respecte, subratllam de bell nou que la reflexió teòrica sobre els clàssics ens ha portat a escollir:

- Com a variable clau la taxa de benefici (r). La taxa de benefici (r) és la part dels beneficis de les empreses de negoci corporatiu no financer $(P)$ en l'estoc de capital, és a dir, $r=\frac{\mathrm{P}}{\mathrm{K}}$. Però, d'altra banda, la taxa de benefici ( $\mathrm{r}$ ) es pot expressar també com a producte de tres factors: el primer, el factor de financiarització de l'economia $(\alpha)$, mesurat com el pes dels beneficis de les empreses de negoci corporatiu no financer (P) en l'excedent brut d'explotació (EBE), on $\alpha=\frac{\mathrm{P}}{\mathrm{BB}^{-}}$; el segon, el percentatge d'excedent brut d'explotació en l'ingrés nacional $\left(\mathrm{q}=\frac{\mathrm{EBE}}{\mathrm{Y}}\right)$ i, l'últim factor, la productivitat del capital $\left(\pi_{\mathrm{K}}=\frac{\mathrm{Y}}{\mathrm{K}}\right)$. Per tant, definim la la taxa de guany $(r)$ com: $r=P / K=Y / K \cdot E B E / Y \cdot P / E B E=\pi \_K \cdot q \cdot a$;

- Alhora, recollim amb la productivitat del capital ( $\pi \mathrm{k})$ la noció clàssica de rendiments decreixents;

- Amb les variables explicatives de (q), que son el salari (w) i la productivitat del treball $\left(\pi_{\mathrm{L}} \pi_{\mathrm{L}}\right)$, hom infereix la noció marxiana de cicle i la teoria del salari òptim de Sylos Labini, i la idea de "la forquilla d'equilibri de q";

- Amb la financiarització de l'economia, que es mesura a partir de ( $\alpha)$, es planteja la idea de crisis financeres desencadenades per la fase del boom d'una nova revolució tecnològica, la qual també pressiona a la baixa la recuperació de la productivitat del capital ( $\pi k$ ), a través de la TITG, ja que $(\alpha)$ expressa a la vegada la participació de la taxa de guany del sector productiu real sobre el total de la taxa de guany de l'economia, de tal manera que si $(\alpha)$ cau això comporta un creixement equivalent de la participació a la taxa de guany de les activitats no productives en el conjunt de l'economia. I, de forma consegüent, via TITG, el desplaçament de les inversions productives cap els àmbits financers especulatius, curtcircuitant-ne la sostenibilitat de les inversions productives i del procés innovador que incorporen. Es reactiven així els rendiments decreixents (Llei de Rendiments Decreixents, LRD) i la sostinguda caiguda al llarg del temps de la productivitat del capital ( $\pi \mathrm{k})$.

A partir de les aportacions teòriques i de la recerca empírica, hom arriba a una conclusió de caire general, que s'avança: identifiquem com a trajectòria dominant del capitalisme, sobretot a partir de mitjans dels anys 1960, una tendència decreixent de la productivitat del capital ( $\pi \mathrm{k})$ que va començar a pressionar a la baixa la taxa de guany ( $r$ ). L'espiral preus-salaris d'aquells anys, que s'accentuà a la segona meitat dels anys 1960, n'és una de les conseqüències de la no resolució d'aquella contradicció principal. La crisi dels setanta, de regulació keynesiana, cedirà pas a un nou sistema de regulació neoliberal, que comporta trobar dos elements, per tal d'estabilitzar la caiguda de la taxa de guany: augmentar, per un costat, la desigualtat via la recuperació de (q); i incrementar la financiarització de l'economia, per la participació dins de la taxa de guany global de l'economia de les activitats procedents de l'especulació en els mercats financers. Això ha permès mantenir més o menys estable la taxa de 
guany global a partir de 1980; però no ha eliminat la contradicció principal, és a dir, la caiguda de la productivitat del capital ( $\pi \mathrm{k}$ ) i la LRD del capital. Fins i tot suposant que (q) es mantingués estable per un nou consens social i fins i tot identificant que la nova fase de la present revolució tecnològica permetés recuperar la productivitat física del capital, en termes monetaris dita recuperació de ( $\pi \mathrm{k}$ ) no es produiria, mentre no es talli l'especulació en els mercats financers i la inflació del preu dels actius. Aquesta inflació dels actius dels béns de capital continuarien pressionant a la baixa la $(\pi \mathrm{k})$ monetària via la TITG i, de retruc, la caiguda o estabilització, però no la recuperació monetària de la (r), que és justament lo que recull el nostre model. És a dir, la força de l'especulació financera és tan contundent avui en dia que, fins i tot, es capaç d'avortar la recuperació econòmica que s'hauria d'haver produït gràcies a la revolució tecnològica. Si més no, amb el que realment ens trobem és amb la continuació dels nivells de rendibilitat d'abans de la crisi, no havent-se produït amb la Gran Recessió una caiguda disruptiva de la taxa de guany i, per tant, amb la possibilitat que l'actual regulació neoliberal en la seva fase de forta financiarització no es plantegi de moment la necessitat urgent de canviar. Això augmenta la probabilitat d'iniciar un cicle recurrent de crisis financeres seguides de fases d'escàs creixement, donant lloc al que s'anomena una crisis secular. ${ }^{5}$

\section{Marx i el cicle productiu}

La tendencia decreixent de la taxa de guany -peça esencial en el nostre treball- no s'entén sense el concepte de renda ricardiana (que David Ricardo només aplicà al factor terra): l'evolució d'aquesta era la causa central de les crisis, des del moment en què una major expansió de les terres de pitjor qualitat, tot cercant de bell nou els beneficis perduts, comportava l'aparició dels rendiments decreixents. Aquests s'engrandien en funció de la posada en concurs d'un sol factor productiu -la terra-, que tensava a l'alça els moviments demogràfics, la qual cosa inferia una major demanda de terres i, amb l'absència d'inversió tecnològica, el perllongament de la tendència negativa dels rendiments. La conclusió és que els guanys cauen per l'aparició de rendiments decreixents; si aquests no es desactiven, els empresaris poden reaccionar tot recuperant la rendibilitat incrementant els preus -és a dir, amb inflació-, i aquest fet farà perdre competitivitat a les possibles exportacions. Aleshores, per a Ricardo la solució no és altra que la defensa del lliure comerç: aquest facilitarà la compra d'aliments -de forma preferencial-, la qual cosa impedirà que es posin en conreu terres marginals i tornar, així, a l'escenari positiu de desenvolupament agrari.

Les situacions concatenades en aquest procés es poden multiplicar en escenaris successius. El bessó de la crisi rau, doncs, en la translació d'aquest esquema ricardià -amb fortes connotacions malthusianes- a l'esfera industrial i, ara, dels serveis: també aquí podien aparèixer els rendiments decreixents si la productivitat del capi-

5 Cf. Blanchard-Summers et alter, Comment on "Inflation and Activity", Laurence Ball, agost de 2015: http://www.econ2.jhu.edu/People/Ball/BlanchardComment.pdf; Fatás-Summers, «The permanent Effects of Fiscal Consolidations», INSEAD, ABFER i CEPR, 2015. 
tal queia, de manera que això llastrava negativament l'evolució dels beneficis empresarials. De fet aquesta ha estat una de les hipòtesis del nostre treball aplicat, és a dir, donar evidència empírica que en les economies capitalistes desenvolupades que presenten una forta terciarització és pot tornar a reactivar la Llei de Rendiments Decreixents (LRD), després d'haver travessat per una fase de forta reindustrialització des de 1945 fins a mitjans dels anys 1960. Aleshores, ja es comencen a notar els efectes negatius de la saturació en els mercats de béns de consum de masses, en la fase madura de la quarta revolució tecnològica, fet que recollim amb la tendència decreixent de la productivitat del capital ( $\pi \mathrm{k})$, a partir d'aquells anys.

El complement a aquesta visió ricardiana és la que proporciona K. Marx (juntament a les seves pròpies aportacions). Aquest estudia el cicle econòmic industrial i fixa una durada a l'entorn de 8-10 anys. Descriu la dinàmica econòmica capitalista de forma cíclica, és a dir, bolcada a caure en crisis periòdiques de sobreproducció. En aquest respecte, les reflexions de Marx en el llibre 1 de El Capital constataven serioses incapacitats del treball assalariat per a adquirir tot el que s'estava produint. És aquesta una de les grans contradiccions del capitalisme industrial, des del moment en què els empresaris cercaven incrementar els seus beneficis tot pagant menys salaris i generant desocupació. ${ }^{6}$ Marx considerava de forma intrínseca els problemes de la manca de demanda com un eix central que penalitzava la possibilitat de seguir acumulant capital, atesa la previsible saturació dels mercats per incapacitats en el consum.

Marx rubricava que la funció gairebé històrica del capital industrial no era altre que la d'alliberar a la societat de les lacres de l'interès i de la renda que el capitalisme industrial havia heretat de l'època feudal. La visió era lògica: aquestes rendes alentien l'acumulació de capital industrial, des del moment en què no naixien del procés de producció. Sobre aquestes idees hom pot formular el següent: sigui una economia tancada on:

$\mathrm{W}=$ Massa salarial; $\mathrm{C}=$ Consum; $\mathrm{B}=$ Beneficis totals; $\mathrm{I}=$ Inversió; $\mathrm{Y}=$ Renda; $\mathrm{r}=$ taxa de beneficis $(\mathbf{r}) ; \mathrm{g}(\mathrm{W})=$ creixement salarial; $\mathrm{g}\left(\pi_{\mathrm{L}} \pi_{\mathrm{L}}\right)=$ creixement de la productivitat del treball; $\mathrm{q}=$ participació dels beneficis en la renda $(\mathrm{B} / \mathrm{Y}) ;(\mathrm{l}-\mathrm{q})=$ participació de la massa salarial en la renda $(\mathrm{W} / \mathrm{Y}) ; \mathrm{L}=$ Ocupació total.

Podem establir aleshores les següents expressions lògiques:

$\mathrm{Y}=\mathrm{W}+\mathrm{B}=\mathrm{C}+\mathrm{I}$

6 F. Engels escrivia al pròleg del primer llibre de El Capital, el 1886 (citam per la versió en castellà): "Mientras que la fuerza productiva crece en progresión geométrica, la expansión de los mercados avanza, en el mejor de los casos, conforme a una progresión aritmética. Es verdad que el ciclo decenal de estancamiento, prosperidad, sobreproducción y crisis que se repitió constantemente de 1825 a 1867 parece haber concluido, pero sólo para sumirnos en la cenagosa desesperanza de una depresión permanente, crónica. El anhelado período de prosperidad no termina de llegar; cada vez que nos parece vislumbrar sus signos precursores, éstos se desvanecen en el aire. Entretanto, cada nuevo invierno replantea la gran cuestión: "¿Qué hacer con los desocupados?"; pero mientras que el número de éstos va en aumento de año en año, no hay nadie que responda a la pregunta, y casi es posible calcular el momento en que los desocupados, perdiendo la paciencia, tomarán su destino en sus propias manos"; Marx, 2010, p. 32. 
Si, de moment, no tenim en compte el el grau de financiarització de l'economía $(\alpha)$, la dinàmica de la distribució de rendes entre salaris i beneficis i la de la taxa de guany $(r)$ es poden expressar de la següent manera:

Si $g(W)>g\left(\pi_{L} \pi_{L}\right)=$ augmentarà la participació dels salaris en la renda $(\mathrm{W} / \mathrm{Y})$; en contrapartida, disminuirà $(\mathrm{q})$ (ja que $\mathrm{q}=\mathrm{B} / \mathrm{Y})$. Per tant, caeteris paribus, la taxa de benefici ( $r$ ) caurà.

Si $g(w)=g\left(\pi_{L} \pi_{L}\right)=$ es mantindrà constant la relació $(W / Y),(q=B / Y)$ i, per tant, també serà constant la taxa de benefici $(r)$ sempre i quan la productivitat marginal del capital ( ) es mantengui constant.

Si $g(w)<g\left(\pi_{L} \pi_{L}\right)=$ disminuirà $(W / Y)$ i, com a contrast, augmentarà $(q=B / Y)$, de manera que s'incrementarà la taxa de benefici $(r)$ sempre i quan la productivitat marginal del capital ( ) no variï.

Llavors en la fase expansiva o de creixement del cicle econòmic tindrem les següents cadenes seqüencials: ${ }^{7}$

( 1) Hipòtesi clàssica del creixement econòmic: $+\mathrm{B}$ (Beneficis) $\rightarrow+\mathrm{I}$ (Inversions productives) $\rightarrow+\mathrm{Y}$ (creixement econòmic).

(2) Hipòtesi marxiana sobre el salari en fase de creixement: $+\mathrm{Y}$ (creixement econòmic) $\rightarrow+\mathrm{L}$ (creixement de l'ocupació) $\rightarrow-$ Atur (caiguda de l'exèrcit de reserva) $\rightarrow+$ poder de negociació salarial per part dels treballadors $\rightarrow+$ w (creixement del salari per treballador o salari unitari) $\rightarrow+\mathrm{W}$ (creixement de la massa salarial total, ja que creix el salari i l'ocupació) $\rightarrow-\mathrm{B}$ (caiguda del benefici si el salari unitari creix més que la productivitat del treball).

Per tant, quan el creixement del salari unitari $\mathrm{g}(\mathrm{w})$ és superior al creixement de la productivitat del treball $g\left(\pi_{\mathrm{L}} \pi_{\mathrm{L}}\right)$, augmenta la participació dels salaris en la renda $(\mathrm{W} / \mathrm{Y})$, mentre disminueix la participació dels beneficis en la renda (q), i també la taxa de guany $(r)$, ja que al final de la fase de creixement els beneficis disminueixen mentre encara augmenta la renda, donant pas a una nova fase recessiva o de contracció de les inversions i del creixement econòmic. ${ }^{8}$

En la fase depressiva del cicle o de crisi econòmica llavors tindrem les següents cadenes seqüencials:

7 Aquestes cadenes es poden consultar a A. Roncaglia, Elements fonamentals d'economia politica, Vic, Eumo Editorial, editorial, 1994.

8 Minqi, «Capitalism with zero profit rate? Limits to growth and he law of the tendency for the fate of profit to fall», working paper, University of Utah, núm. 2007-05, www.econstor.eu/dspace/ bitstream/10419/64451/1/572640692.pdf. 
(3) Hipòtesi sobre la competència de capitals: - B (caiguda de beneficis) $\rightarrow-\mathrm{L}$ (la caiguda de beneficis induïda per la caiguda de la demanda reforça la competència entre les empreses i comporta la necessitat de reduir els costos salarials via la disminució de l'ocupació) $\rightarrow+g\left(\pi_{\mathrm{L}} \pi_{\mathrm{L}}\right)$ (l'acomiadament de treballadors es fa de forma selectiva, de tal manera que els més productius poden mantenir el seu lloc de treball i escometre noves funcions productives en un procés de racionalització dels processos productius i d'augment de la productivitat del treball).

(4) Hipòtesi marxiana sobre el salari en la fase de decreixement: - L (caiguda de l'ocupació) $\rightarrow+$ Atur (augment de l'exèrcit de reserva) $\rightarrow$ - poder de negociació del salari per part dels treballadors $\rightarrow-\mathrm{W}$ (decreixement del salari unitari) $\rightarrow-\mathrm{W}$ (decreixement de la massa salarial total, ja que cau el salari i l'ocupació) $\rightarrow+B$ (recuperació del benefici si el salari unitari creix menys que la productivitat del treball).

Quan el creixement dels salaris és inferior al de la productivitat del treball, la distribució de la renda varia en contra dels treballadors, atès que cau la participació dels salaris a la renda, a l'ensems que augmenta la participació dels beneficis i, de retruc, la taxa de guany. Es dona pas a una nova fase expansiva, de creixement de les inversions i de l'economia, tot i que amb increment de la desigualtat i empobriment de la classe treballadora. Sobre aquest punt, és interessant la interpretació de Sylos Labini, que es centra en posar en valor el concepte del "salari d'equilibri", hipòtesi central del nostre treball aplicat a l'hora de definir la la forquilla d'equilibri de (q).

El contrast històric rubrica les expressions assenyalades, de manera que hom poden detectar vigències evidents en aquestes seqüències. Si hom adopten els fets estilitzats per a l'economia contemporània, podem observar que en l'economia nord-americana es veu, des de la postguerra, un període que abasta els anys 19451965 on, segons les recerques fetes, predominà l'equilibri entre el creixement salarial i el de la productivitat del treball, de manera que es va mantenir força estable la distribució de la renda i la desigualtat social. ${ }^{9}$ Sobre aquest punt, el recent treball de T. Piketty ${ }^{10}$ incideix en tal plantejament, a partir de la corba indicativa de la desigualtat econòmica (en forma de "U", tot agafant el període 1910-2010, sobre dades fiscals). La fase que s'enceta els anys 1970 es correspon amb la crisi econòmica -amb signes a les acaballes de la dècada dels anys 1960-, caracteritzada per xocs de costos productius -augment de salaris i de preus, arran sobretot de l'increment dels preus del petroli-, que suposaren creixements salarials que pogueren anar per sobre dels corresponents a la productivitat del treball. A partir de la crisi dels anys 1970--com en el decurs de la Gran Depressió- hom assisteix a un increment salarial que està per sota del de la productivitat del treball: s'inauguren aleshores períodes de desigualtat social. En suma: la fase de la regulació keynesiana (a partir de 1945) és la de màxima estabilitat en el creixement econòmic i quan es produeix una major estabilitat en la distribució de la renda. Els indicadors al respecte són copiosos i demostren un fet

9 Milanovic 2006; Crafts-Fearon 2013.

10 Piketty 2013, 2014. També: Schui 2014. 
rellevant: ${ }^{11}$ el creixement de l'economia no depenia de la major o menor eficiència del mercat, sinó d'una resolució -en aquest cas positiva- del conflicte distributiu entre capital i treball.

De nou, però, es fa necessari recórrer als aspectes financers no integrats en aquest esquema inicial del cicle econòmic. Ens referim als que fan esment al procés de financiarització econòmica, que al llarg dels anys anteriors a la crisi dels anys 1970 no es fan notar. De fet, en el cas de l'economia dels Estats Units la participació dels beneficis de les empreses no financeres sobre el totals dels excedents empresarials $(\alpha)$ presenta el seu valor màxim el 1966, iniciant-se a partir d'aquell any el seu declivi i pressionant a la baixa la taxa de guany. ${ }^{12}$ Així, al llarg dels anys 1960 el crèdit al consum i a la compra d'habitatges es manté en taxes de creixement contingudes, ja que bona part del creixement de la demanda de les famílies es troba sostingut pel propi creixement salarial, la qual cosa, canviarà radicalment a partir dels anys 1980 amb la implantació de la nova regulació neoliberal, on el consum i la compra d'habitatges serà esperonat, en bona part, gràcies a l'expansió de la financiarització de l'economia. ${ }^{13}$ Aquest plantejament pot ser escaient en la conjuntura econòmica actual, on el domini del capital financer sobre l'industrial sembla evident. Això és, probablement, el que no albirà Marx en tota la seva dimensió, per la qual cosa mereix al nostre entendre una especial atenció la noció de la Tendència a la Igualació de la Taxa de Guany (TITG) de G. De Bernis.

L'actual fase de sortida de la crisi no té garantida la seva solvència, mentre no es reequilibri de nou el creixement del salari amb el de la productivitat, l'increment de la participació dels beneficis a la renda en detriment dels salaris comporta un increment tant de la desigualtat com de la dificultat de mantenir el consum per part dels assalariats. Aquests, per suportar els seus nivells de consum, s'hauran d'endeutar progressivament fins a extrems que faran inviable el manteniment a l'apel-lació a nous processos de finançament. Aquest és l'escenari que s'enceta arran de la nova regulació neoliberal, a partir dels anys 1980, amb la proliferació de bombolles creditícies i extensió de la desigualtat. D’alguna forma, ens trobem en un escenari que tal vegada té més encaix en formes econòmiques de caire pre-capitalista, en el sentit industrial del concepte "capitalista". Ara, finances i rendes estan guanyant la batalla a l'industrialisme, tot imposant això que I. Fisher qualificà, el 1933, com "deflació per deute", un fenomen que afecta de manera molt directa al factor treball. ${ }^{14}$ Dit amb altres paraules: la visió de la crisi no pot negligir, de cap forma, aquesta realitat, que massa sovint és relegada pels mateixos autors marxistes. ${ }^{15}$ En efecte, els costos que

11 Marglin-Schor 1990; Ziliak-McCloskey 2008.

12 Manera-Navinés-Franconetti 2015.

13 Cooper 2009; Foley «The Political economy of post-crisis global capitalism», Universidat de Chicago, https://sites.google.com/a/newschool.edu/duncan-foley-homepage/home/downloads., 2010; Reinhart-Rogoff, «Financial and Sovereign Debt Crises: Some Lessons Learned and Those Forgotten», FMI working paper 13/266, 2013, https://www.imf.org/external/pubs/ft/wp/2013/ wp13266.pdf.

14 Fisher 1933; Keen 1995.

15 Sobre això, vegeu Katz 2010. 
representen mantenir les càrregues de deute (interessos, amortitzacions) erosionen el mercat de productes, des del moment en què absorbeixen la part del lleó dels negocis. Per tant, resta menys marge per a l'assignació de recursos en béns i serveis, de forma que es generen crisis de sobreproducció. I la incidència sobre els salaris darrera la caiguda de guanys provoca, al seu torn, problemes a la demanda: el subconsum s'esdevé, aleshores, com l'altra peça a considerar.

La relació d'això amb els mercats immobiliaris és clara: en lloc de promoure més formació de capital, els mercats de valors transfereixen recursos a béns arrels, una canalització inversora que, en el decurs de la Gran Recessió -i en els seus orígens- té a veure amb les intenses assignacions de recursos a les compres immobiliàries i de solars (en essència, doncs, de terra) que, alhora, serveixen com a actius per als bancs. Són una notòria garantia per a ells. El sistema financer juga, aleshores, un paper consemblant al que desenvolupà el factor terra en la visió de les crisis que tenia Marx: els seus detenidors es feien amb el valor creixent de les rendes del sòl. En el moment en què escrivia Marx, el patró monetari i econòmic estava regit sota les regles del patró or. Els seus mecanismes equilibradors portaven, com a llavor central, el funcionament bàsic del capital industrial: gaudir d'or provocava tot un seguit de processos tendents a pujar o davallar els tipus d'interès -en funció de les trajectòries de les balances comercials-, a esperonar per tant -o no- les inversions productives i, per tant, a impactar sobre el mercat de treball en forma de majors o menors contractacions (amb incidències sobre preus i salaris). ${ }^{16}$ Però la base central no era el capital financer, sinó l'industrial. De fet, Marx confiava que aquest darrer acabaria per ensorrar el primer: reduiria les pràctiques agiotistes, especulatives, que ell adscrivia al sistema de producció feudal. La usura era, en aquest sentit, l'expressió genuïna d'aquest procés. La influència d'altres ciències en ebullició és present en aquesta visió marxiana: una mena de darwinisme econòmic que venia a dir que la fortalesa del capital industrial s'imposaria sobre aquelles excrecències del capital financer, contaminat encara per les formes feudals de producció, on la formació de capital -és a dir, la separació estricta entre producció i distribució- acabaria guanyant la partida en la seva forma superior: el triomf del capital industrial. En aquestes coordenades, el mateix capital comercial era una part més del capital industrial, generat per la lògica de la circulació.

Marx no contemplava, de cap manera, la possibilitat de que es "creàs" diners del no-res. Fer ho significaria la gènesi d'expansions forçades, per la qual cosa ara li resultaria força complicat entendre com ha estat possible aquest domini aclaparador de les finances sobre el món estrictament industrial. Un domini que, tal i com intuí Fisher, conduïa indefectiblement a problemes severs de demanda: quan els serveis del deute per pagar als bancs el que fa és desviar ingressos de manera que hom impedeix gastar-los en inversions i consums -el que J. M. Keynes bateja com demanda agregada, en definitiva-, ens trobem en un escenari de deflació per deute. Aquesta darrera augmenta cada cop més, alhora que la manca d'acumulació de ca-

16 Eichengreen 1998. 
pital penalitza els nivells salarials des del moment en què l'assoliment dels beneficis, front a la caiguda de la productivitat del capital, es fa tensant a la baixa els salaris.

Els canvis a les estructures econòmiques des dels anys 1950, amb pes determinant del sector serveis i l'avenç de la "terciarització", han imposat la "desaparició" de la mercaderia física com a objecte central. Ara, són els serveis, una nebulosa sovint difícil d'albirar, la que regenta l'avenir econòmic, i això infereix al seu torn canvis socials de primera magnitud: la descomposició de la vella classe obrera i la segmentació del treball i dels treballadors en una constel-lació complexa de realitats sovint enfrontades. ${ }^{17}$ Això trenca igualment amb la nostra visió més convencional de la teoria del valor, i no ens podem refugiar, de forma acrítica, en la perspectiva "industrialista" quan la realitat econòmica l'ha reinterpretada, tal vegada amb la excepció d'algunes economies emergents, com per exemple la xinesa. Però també aquesta darrera correrà amb la mateixa sort que les occidentals, des del moment en què l'allau d'inversions en béns immobiliaris -la terra, de bell nou- farà pujar els preus de forma persistent -com s'ha esdevingut a economies avançades-, sense que hi hagin gravàmens ni frens disponibles per a apaivagar aquest procés. ${ }^{18}$

Per tant, de l'aportació marxista es poden derivar teories subconsumistes, un tema que després apareixerà amb força a la Teoria General de Keynes. El que Marx no suposava és que aquell capital industrial tendent a arraconar per sempre més el financer acabaria per perdre la partida econòmica. Ara, ens situem en un escenari de major financiarització de l'economia del què hom podia intuir fa uns anys. Emperò, l'economia actual té en escassa consideració aquests punts, alhora que molts autors marxistes no ho treballen perquè el seu centre d'anàlisi rau, justament, en un capital productiu que a hores d'ara ha perdut capacitats tangibles en el procés de formació del capital. En dit context, una solució post-keynesiana, defensada per Sylos Labini, radica en la idea de que es pot recuperar la distribució de la renda abans de la crisi econòmica si el salari s'incrementa al mateix ritme que la productivitat, a mesura que la nova fase de creixement permet recuperar el poder de negociació per part de les organitzacions sindicals. També aquí la noció de domini del capital financer hi és ben present, i en el nostre model, l'altre condició necessària per sortir de la crisi és la recuperació de la (r) real en detriment de la taxa de guany financera (rf), per tal de què es puguin neutralitzar els efectes negatius que a través de la TITG es poden desencadenar sobre la productivitat del capital $(\pi \mathrm{k})$.

\section{Schumpeter o el complement a Marx. L'aparició de les economies de serveis}

La superació d'aquesta realitat aparentment bloquejada pot ser possible a través de processos innovadors. En aquest aspecte, el plantejament heterodox de J. A. Schumpeter enriqueix el de Marx en dues direccions: per un costat, l'alemany analitza el cicle industrial de 8 a 10 anys, mentre l'austríac fa servir, essencialment, l'ona

17 Gordon-Edwards-Reich 1986; Austin et alter 2013.

18 Sobre tot això: Garnaut-Song-Golley 2010; Garnaut-Song 2012. 
llarga de 50 a 70 anys -molt en la línia de Kondratieff- sustentat sobre les innovacions fonamentals; per altra banda, hom introdueix a l'anàlisi del cicle econòmic el comportament del crèdit bancari, un aspecte crucial per a entendre correctament la Gran Recessió. La línia argumental de Schumpeter es pot estilitzar així:

- En un primer moment, s'origina una embranzida de clústers de noves innovacions, que permeten generar alhora noves oportunitats de negocis i beneficis extraordinaris per part de les empreses innovadores. Aquestes són imitades per altres, de forma que hom origina un cicle expansiu que obre, en paral-lel, altres perspectives de negocis al sector financer mitjançant els crèdits a empreses i famílies per tal de facilitar el seu consum. Això contribueix a minvar la morositat d'aquelles, la qual cosa esperona una nova bombolla creditícia que esdevé en una nova fase de sobreinversions. És així com s'arriba a una saturació dels mercats i a un excés d'oferta que dibuixa el final de la fase expansiva del cicle.

- Aleshores, hom assisteix a una caiguda de les vendes empresarials i dels beneficis, la qual cosa porta a una reducció de les inversions i del creixement econòmic. Això reverteix en un menor retorn de rendes i en un increment de la morositat d'empreses i famílies. Front això, el sector financer reacciona amb retallades en els crèdits, de manera que agreuja l'aturada inversora i propicia una contracció important de la producció. El problema planteja sengles solucions: la destrucció del capital sobrant; o l'acceleració de les innovacions que propiciïn un nou esclat de clústers, de forma que es cedeix pas a un nou cicle d'ona llarga de creixement.

Aquestes línies mestres d'interpretació s'han complementat amb els treballs de H. Minsky i C. Pérez, que es sustenten en l'avenç de la desigualtat quan es produeix el fenomen d'ajustament econòmic. Ambdós autors indiquen que la desigualtat s'incrementa de forma notòria quan es desenvolupen bombolles especulatives, les quals tenen, com a origen clau, una revolució tecnològica a la què cal sumar el desplegament de polítiques de desregulació dels mercats financers. El contrast històric de tot plegat és identificable a la Gran Depressió i a la Gran Recessió (vegeu taula 1).

A partir de la periodificació de C. Pérez, la cinquena revolució tecnològica s'inicia a la dècada dels anys 1970 i s'imposa amb el neoliberalisme el 1980 tot arribant fins a l'actualitat. En el treball sobre l'economia dels Estats Units, les tendències de fons que hem trobat en aquest període 1980-2013, respecte al període anterior són bàsicament tres: primera, la caiguda de la taxa de benefici (r); segona, la caiguda de la productivitat del capital ( $\pi \mathrm{k})$ i del creixement de la relació capital-renda $(\mathrm{K} / \mathrm{Y})$; i tercera, l'augment de la quota participativa dels excedents (q) i de la desigualtat (que hom adverteix, igualment, a les corbes construïdes per T. Piketty). Una pregun- 
ta clau és perquè es dóna aquesta caiguda de la productivitat del capital. ${ }^{19}$

Taula 1. Gran Depressió i Gran Recessió: factors essencials i comparativa

\begin{tabular}{|c|c|c|}
\hline Factors essencials & Abans de 1929 & Abans de 2008 \\
\hline \multirow[t]{6}{*}{ Inici đuna nova revolució tecnilògica } & Fond T & Onfmaiders \\
\hline & Electrodomástics & TIC \\
\hline & Flastirs & Intemet \\
\hline & Cinema & Puntncom \\
\hline & Publicitat & Globalitació financern \\
\hline & Thrisme & \\
\hline \multirow[t]{5}{*}{ Beneficis extrandi i empreses tradnres } & Ford & Microsofit \\
\hline & General Motnes & Apple \\
\hline & Exxon & Googie \\
\hline & General Electric & \\
\hline & Westinghnuse & \\
\hline \multirow[t]{4}{*}{ Novesactivitats, +crềift, +ocuparió } & Descens atur & Descrens attr \\
\hline & Angement del crìdit & Angement del crùtift \\
\hline & Noves utbanitzaions & Noves ubanitzacions \\
\hline & Compres a placas & Compres a plagos \\
\hline \multirow[t]{2}{*}{ Gènesi de bombolles, exhuberincia imarional } & Mitificació dels imversos & Mitificarió dels imversurs \\
\hline & Nans proudactes de derivats & Nans prodhactes de derivats \\
\hline \multirow[t]{4}{*}{ Efectes Ponzi actmacions frandilentes, especilarió } & Charies Ponzi & BemardMailofi \\
\hline & Moody & Stanibrs:Poor's \\
\hline & Poor's & Price WaterthanseCoopers \\
\hline & Fitrh & Fitnh \\
\hline Bombolles promuten la desiguritat social & Dailes reonllides per Thamas Pîtretty & Dades recollides per Themas Fiketty \\
\hline
\end{tabular}

Font: elaboració pròpia.

\section{Una anàlisi aplicada}

\section{El model de la taxa de guany}

Per a atendre a aquestes qüestions, cal tenir en compte com vàrem adaptar, a la secció 1 , la definició de la taxa de guany en una economia fortament financiaritzada com l'actual, i on es tracta de maximitzar els creixements monetaris o més estrictament crematístics, per la qual cosa totes les variables estan expressades en termes monetaris. Així doncs, tenim les següents equacions:

Equació 1. La quota d'excedent brut d'explotació, (q):

$q=1-\frac{W}{Y}=1-\frac{\frac{W}{L}}{\frac{Y}{L}}=1-\frac{w^{*}}{\pi_{L}}$

On:

$\mathrm{W}=$ rendes del treball;

$\mathrm{EBE}=$ rendes del capital;

$\mathrm{Y}=$ Renda o Valor Afegit Brut a cost dels factors $=\mathrm{W}+\mathrm{EBE}$;

$\mathrm{W}^{*}=$ cost laboral unitari o salari;

19 Vegeu al respecte l'informe del FMI, https://www.imf.org/external/pubs/ft/sdn/2015/sdn1503. pdf. A diferència d'aquest text del FMI, que treballa sobre la hipòtesi de la Productivitat Total dels Factors (PTF), nosaltres treballem sobre la hipòtesi de la productivitat del capital i la seva dependència de la TITG. 
$\pi_{\mathrm{L}} \pi_{\mathrm{L}}=$ productivitat del treball;

Hom permet apreciar que es pot donar una perfecta estabilitat de la participació de les rendes del capital en la renda nacional (q), només si s'iguala la taxa de creixement del salari ( $\mathrm{gW}^{*}$ ) amb la taxa de creixement de la productivitat del treball $\mathrm{g}\left(\pi_{\mathrm{L}} \pi_{\mathrm{L}}\right)$. En cas contrari, si el cost laboral unitari creix més o menys que la productivitat del treball tindrà com a efecte una disminució o un augment corresponent de la quota d'excedent (q). Per tant, l'equilibri en la distribució funcional de la renda entre les rendes del capital i les rendes del treball passa per observar que els salaris creixin en els mateixos termes que ho faci la productivitat del treball.

Equació 2. La taxa de benefici:

$$
\mathbf{r}=\frac{\mathbf{Y}}{\mathbf{K}} * \frac{\mathrm{EBE}}{\mathbf{Y}} * \frac{\mathbf{P}}{\mathrm{EBE}}=\pi_{\mathrm{K}} * \mathbf{q} * \alpha
$$

Per a la taxa de benefici, la productivitat del capital representa la seva tendència principal de fons, i la seva taxa de creixement ve fortament condicionada per la velocitat en la qual s'introdueix el canvi tecnològic en el conjunt de les activitats productives. Els altres dos factors actuen de contra-tendència del primer. Així, la quota d'excedent (q) ens informa sobre el repartiment de la renda, la qual cosa al seu torn reflecteix el grau de desigualtat en una economia. De fet, es pot donar una recuperació de la taxa de benefici mitjançant un augment de la desigualtat a través d'un augment de $(q)$.

El factor de financiarització $(\alpha)$ s'interpreta com la inversa del grau de financiarització d'una economia, és a dir, mesura d'alguna forma el pes dels sectors real i financer en una economia al llarg del temps; per exemple, un factor de financiarització per sota d'l indica que P és menor que EBE, la qual cosa inferiria que el sector financer de l'economia creix per sobre del real, ja que l'excedent augmenta més que els beneficis de les empreses no financeres. Si R són els excedents de les empreses financeres que no es comptabilitzen com a P i s'inclou en EBE, llavors tenim:

Equació 3. L'excedent brut d'explotació:

$$
\mathrm{EBE}=\mathrm{P}+\mathrm{R}, \mathrm{y} 1=\alpha+\frac{\mathrm{R}}{\mathrm{EBE}} 1=\alpha+\frac{\mathrm{R}}{\mathrm{EBE}}
$$

Per tant, si $(\dot{\alpha}<1)(\dot{\alpha}<1)$, llavors $\left(\frac{\dot{\mathrm{R}}}{\mathrm{EBE}}\right)>1 \mathrm{i} \dot{\mathrm{R}}>E \dot{B} E>\dot{\mathrm{P}}$. Això implica que valors alts de a indiquen menys financiarització de l'economia i valors més baixos constaten el contrari. 
En paral.lel, podem definir en aquest model de la taxa de guany la Tendència a la Igualació de la Taxa de Guany (TITG) de la següent manera:

Sigui $(r)$ total $=(r)($ sector real $)+(r)($ sector financer $)=(r)+(r f)$;

On: $(r)=\mathrm{P} / \mathrm{K}$; i $(\mathrm{rf})=\mathrm{R} / \mathrm{K}$, i per tant $(\mathrm{r})$ total $=\mathrm{EBE} / \mathrm{K}$, ja que: $\mathrm{P}+\mathrm{R}=\mathrm{EBE}$.

I podem expressar la participació de la taxa de benefici del sector real i del sector financer sobre la $(r)$ total com:

(r) total $/(\mathrm{r})$ total $=1=(\mathrm{r}) /(\mathrm{r})$ total $+(\mathrm{rf}) /(\mathrm{r})$ total;

on $(r) /(r)$ total $=\mathrm{P} / \mathrm{K} / \mathrm{K} / \mathrm{EBE}=\mathrm{P} / \mathrm{EBE}=(\mathrm{a})$;

$\mathrm{i}(\mathrm{rf}) /(\mathrm{r})$ total $=\mathrm{R} / \mathrm{K} / \mathrm{K} / \mathrm{EBE}=\mathrm{R} / \mathrm{EBE}=(1-\mathrm{a})$.

Per tant, en el nostre model un augment de $(\alpha)$, també indica un augment de la participació de la taxa de guany real sobre la taxa de guany global de l'economia; quan aquesta augmenta, està indicant que també estan creixent més les oportunitats de negoci rendibles en l'esfera real que en l'esfera financera i a l'inrevés.

\section{Tot aplicant la teoria: I'anàlisi de l'economia dels Estats Units}

En aquest apartat s'estableix la periodificació del cicle econòmic a partir de l'evolució de la quota d'excedents (q). Aquesta elecció parteix de considerar a aquesta variable com la més adequada per a periodificar les ones llargues que es produeixen per la dinàmica capitalista, ja que permet, d'una banda, mesurar l'evolució de la desigualtat social en el repartiment de la riquesa des de la perspectiva de la comptabilitat nacional i, per una altra, anticipar el comportament del PIB en funció que els valors de la quota d'excedents (q) es trobin o no dins del que es defineix com la forquilla d'equilibri $\left(q^{*}\right)$. Per a Sylos Labini, els períodes d'estabilitat dels animals spirits, en els quals es maximitza el creixement del PIB real, es caracteritza per complir la regla que defineix la forquilla d'equilibri de la participació dels excedents empresarials en el PIB $\left(q^{*}\right)$. Aquesta regla de comportament que infereix els períodes d'equilibri de $\left(q^{*}\right)$ es caracteritza perquè en ells es percep una tendència a negociar els convenis col-lectius, de tal manera que la taxa de creixement dels costos laborals unitaris ( $\mathrm{w}$ ) es faci d'acord amb el creixement de la productivitat del treball $\left(\pi_{\mathrm{L}} \pi_{\mathrm{L}}\right)$.

En el cas que es doni una igualtat exacta entre les dues taxes de creixement, el valor de (q) roman estàtic i, per tant, es dóna un període de perfecta estabilitat en la distribució de la renda entre salaris i excedents empresarials. En l'economia real, difícilment les dues taxes de creixement casen a la perfecció, però si en l'àmbit dominant de la negociació dels convenis col-lectius es perfila per part de les grans empreses un pacte salarial d'aquest tipus, llavors el gruix de l'economia tendeix a reflectir un procés de recuperació del creixement econòmic alhora que es dóna també un cert procés d'estabilitat en la distribució de la renda, la qual cosa permet inferir i obtenir els valors d'equilibri de la participació dels excedents en la renda nacional $\left(q^{*}\right)$. 
En aquest treball, la font essencial ha estat una de les principals bases de dades oficials dels Estats Units: el Bureau of Economic Analysis (BEA) i el National Income and Product Account (NIPAs). Per a la sèrie quota d'excedent (q), s'ha treballat la base de dades National Income by Type of Income, Taula 1.12. La quota d'excedent (q) ve definida com a quocient entre els excedents bruts d'explotació i la sèrie de valor afegit brut. L'excedent brut d'explotació s'ha calculat restant a National Income (fila 1) la Compensation of Employees a la qual s'ha sostret "Employer contributions for employee pension and insurance funds" (files 2 menys 7). A la resultant, s'ha dividit per National Income (fila 1). La justificació de restar les contribucions a fons de pensions, pòlisses d'assegurances, bons, etc. de la massa salarial total, s'explica perquè entenem que l'origen del finançament d'aquests fons s'ha fet a partir dels excedents de les empreses i, per tant, formen part dels mateixos, ja que l'increment d'aquests fons és molt significatiu a partir de 1980 i en la seva major part s'inclouen en les retribucions dels alts executius. Tal increment es dóna quan justament s'alenteix el creixement mitjà del salari per treballador, que no inclou aquests emoluments. La taxa acumulativa del PIB s'ha pres de la Taula 1.12, National Income, fila número 1. Per a l'obtenció de la sèrie sobre participació a la renda nacional, s'ha consultat la base de dades de Piketty (http://piketty.pse.ens.fr/fr/), aplicant el filtre Hodrick-Prescott per a l'obtenció de la seva tendència. Per al càlcul de la taxa de guany, s'ha tingut en compte la seva obtenció com a quocient entre l'excedent brut d'explotació i la productivitat del capital que, al seu torn, és el quocient entre el valor afegit brut i el capital, els valors del qual s'han pres de la base de dades Fixed Assets Taula 6.1: "Current-Cost Net Estoc of Private Fixed Assets by Industry Group and Legal Form Organisations", fila 4 "Corporate Senar Financial".

El període en el qual es va produir la màxima estabilitat de la (q) en l'economia d'Estats Units des de 1910 a 2013 va ser al llarg de la fase de regulació keynesiana. Més concretament, la forquilla d'equilibri $\left(q^{*}\right)$ es va produir des de 1950 a 1968, amb la plena vigència del Tractat de Detroit, amb unes característiques determinades: ${ }^{20}$

- Els salaris van poder mantenir el poder de compra i la sostenibilitat del consum agregat de l'economia, sense apel-lar a un endeutament creixent i excessiu per part de les llars.

- Els excedents empresarials i les seves expectatives de creixement, gràcies a l'augment sostingut de la demanda de consum, van ser suficients per mantenir els animals spirits favorables al sosteniment del finançament de les inversions, el creixement econòmic i l'ocupació.

Els valors de la forquilla d'equilibri $\left(q^{*}\right)$ oscil.la entre un valor màxim de 0,42 obtingut en 1942, on Estats Units supera la crisi de 1929 entrant en una economia bèl-lica; i un mínim de 0,40 presentat en 1968, últim any de vigència del Tractat de Detroit a Estats Units. Aquesta fase, 1942-1968, és la que qualifiquem com de regulació keynesiana, mentre la que abasta els anys 1980-2000 es correspon a la regula-

20 Bellatini-Delbono 2013; Blanchard et alter 2012. 
ció neoliberal. ${ }^{21}$ La diferència entre aquestes dues fases de regulació dins de $\left(q^{*}\right)$ és que mentre en la keynesiana el consum de les famílies se sustenta en el creixement dels salaris i de la productivitat del treball, en la neoliberal, a causa del control que s'exerceix en el creixement salarial, el consum de les famílies es finança a través d'un recurs creixent al crèdit, que aboca inexorablement a la formació d'una bombolla crediticia i finalment en la Gran Recessió. Al seu torn, la bombolla crediticia es retroalimenta, sobretot a partir de 1980, de la creixent desigualtat en la distribució de la renda. ${ }^{22}$

Alhora, els desequilibris que es produeixen quan se surt de la forquilla d'equilibri de la participació dels excedents empresarials en el PIB $\left(q^{*}\right)$ suposen:

- Que si el creixement de la demanda de consum es relaciona amb el creixement dels costos laborals unitaris ( $w$ ) i amb l'ocupació; i

- Que si el creixement de l'oferta agregada es relaciona amb el de la productivitat del treball $\left(\pi_{L} \pi_{\mathrm{L}} \pi_{\mathrm{L}}\right)$ i amb l'ocupació.

Aleshores, per a un determinat creixement de l'ocupació, si la taxa d'augment dels costos laborals unitaris ( $\mathrm{w}$ ) no s'ajusta, per excés o per defecte, a la del creixement de la productivitat del treball $\left(\pi_{L} \pi_{\mathrm{L}} \pi_{\mathrm{L}}\right)$, que permet assegurar valors de $(\mathrm{q})$ dins de la forquilla d'equilibri $\left(q^{*}\right)$, llavors els creixements de la demanda i el de l'oferta agregada no s'equilibren. Si és per excés del creixement salarial, es poden crear problemes d'inflació generats per excessius costos de producció i es fa difícil mantenir al llarg del temps la competitivitat internacional de l'economia, produint-se una crisi per estangflació com l'observada en la dècada dels anys 1970, agreujada pels dos cracs petrolífers de 1973 i 1979-1980. Si és per defecte de creixement salarial, es generen problemes de demanda i excés d'oferta, podent-se desencadenar un procés d'ajust amb caiguda de preus. ${ }^{23}$

Tal com mostra el gràfic l, l'evolució de (q) anticipa el comportament de la taxa de creixement anual acumulativa del PIB, en el sentit de preveure caigudes en la seva evolució, quan els valors de $(q)$ es troben fora de la forquilla d'equilibri $\left(\mathrm{q}^{*}\right)$, i recuperacions o manteniment del seu creixement quan (q) retorna als seus valors d'equilibri. El comportament d'aquesta variable és capaç d'albirar les tres grans crisis que l'economia nord-americana ha experimentat al llarg dels últims cent anys: la de 1929 i l'actual, que són crisi de demanda en la qual (q) pren valors per sobre dels d'equilibri; i, d'altra banda, la crisi dels setanta que és de costos de producció per un excessiu creixement dels salaris en els quals els valors de $(q)$ se situen per sota dels d'equilibri.

En el gràfic 2, en el qual es representa únicament la taxa de benefici ( $r$ ) en tendència, s'han marcat una sèrie de línies i fletxes que permeten visualitzar amb facilitat els períodes de les regulacions keynesiana i neoliberal, juntament amb la fase de crisi dels 1970 que va ocasionar el canvi de regulació. Així, es pot observar que

21 Harvey 2014.

22 Bricall 2013.

23 Cf. Blanchard 2006; Blanchard-Leigh 2013. 


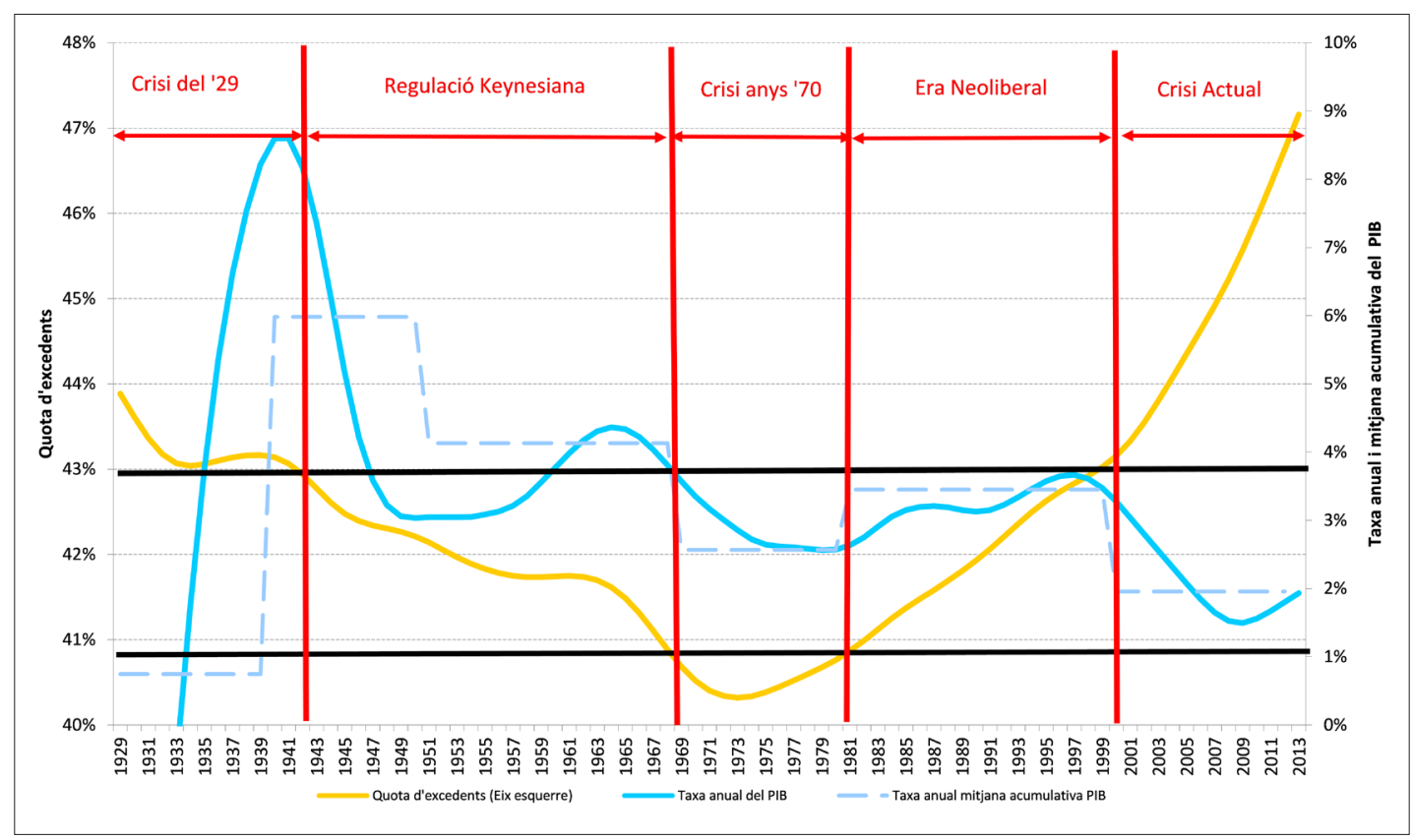

Gràfic 1. EE.UU. Quota d'excedents i creixement del PIB en termes reals a preus 2009 (1929-2013)

Font: Elaboració pròpia

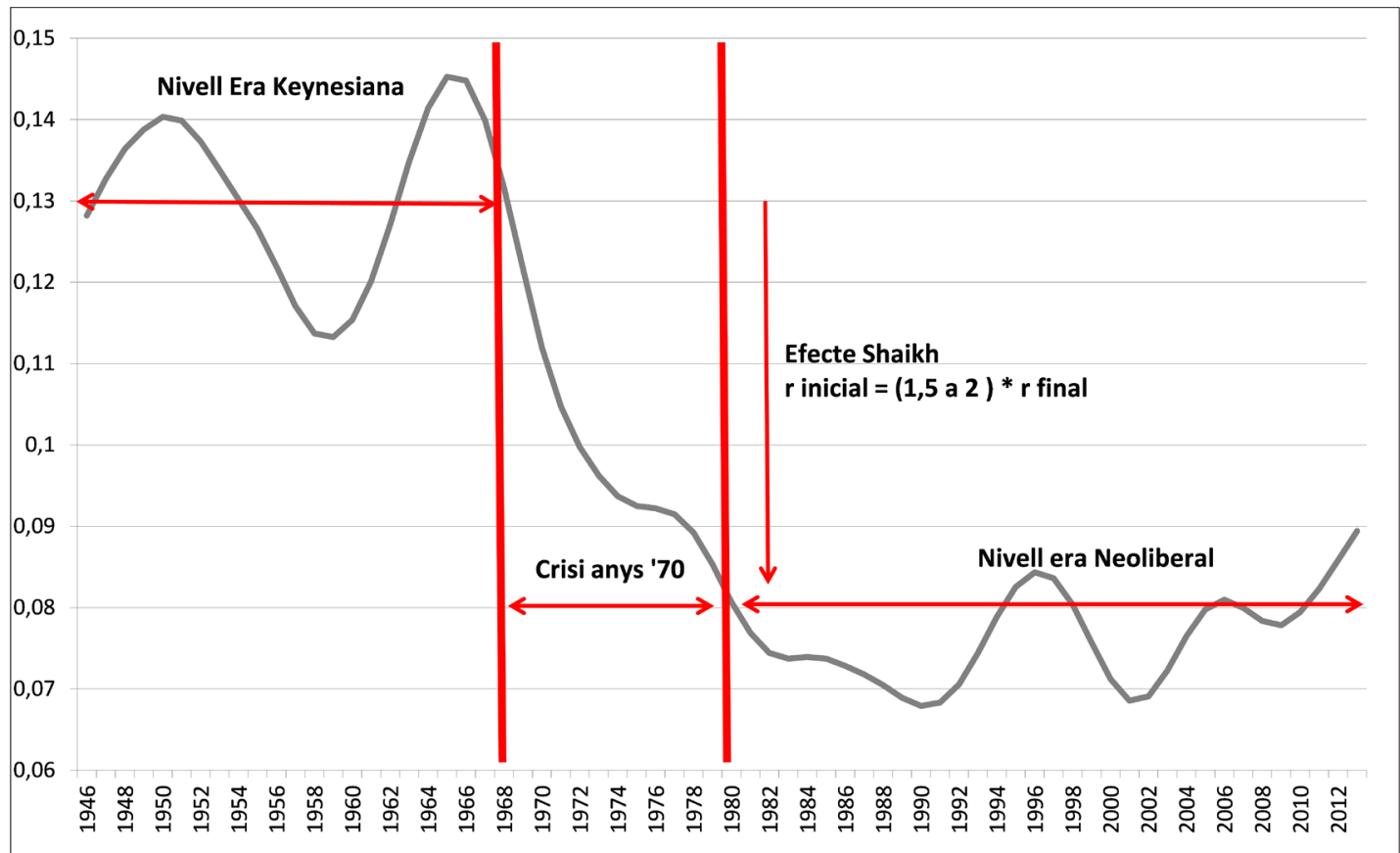

Gràfic 1. EE.UU. taxa de benefici

Font: Elaboració pròpia

la caiguda de la taxa de benefici al llarg dels anys setanta va ser molt significativa, és a dir, estam front una caiguda disruptiva que provoca una doble necessitat: la d'accelerar el canvi per la introducció d'una nova pauta tecnològica, que és el que es va produir a partir de $1971 \mathrm{amb}$ l'inici de la cinquena revolució tecnològica basada en les TIC; i la necessitat de buscar una nova manera de regulació, a través de la substitució de l'era keynesiana per l'era neoliberal, tot contribuint l'èxit dels dos 
processos a evitar que es continuï produint la caiguda disruptiva de la taxa de beneficis a partir de 1980.

En el gràfic s'identifiquen amb claredat tres períodes: el primer va de 1946 a 1968, on s'observa que la taxa de benefici roman estable amb un valor mitjà entorn d'un 13\%; el segon període comença en 1968 i acaba en 1980, i recull l'enorme impacte que la crisi dels 1970 va tenir en els beneficis i que es reflecteix en una caiguda substancial que es deté en el tercer període, que abasta de 1980 a 2013. Estam aleshores inserits en la regulació neoliberal, amb un valor mitjà de la taxa de benefici entorn d'un 8\%: el que hom pot qualificar com "efecte Shaikh", o descens brusc i molt pronunciat de la taxa de guany des de l'inici al final d'una crisi de regulació, de tal manera que el valor final de la taxa de guany s'ha de multiplicar per un factor entre un 1,5 a 2 per aconseguir el valor que aquesta tenia a l'inici de la crisi de regulació. ${ }^{24}$ També és pot observar que aquesta caiguda disruptiva en la taxa de guany no és produeix en la crisi actual o Gran Recessió, per la qual cosa, no s'albira la necessitat, que sí va tenir el sistema en la crisi dels 1970, de mudar cap a un altre mode de regulació. Tot seguit, passem a analitzar aquest comportament de la taxa de benefici a partir de les seves variables explicatives: el factor de financiarització, la quota d'excedent i la productivitat del capital.

La dinàmica de la taxa de benefici i les seves variables explicatives $\left(\pi_{k}\right),(q) i(\alpha)$, permeten inferir els següents patrons en el comportament de l'economia d'Estats Units, quantificats en la taula 2.

Taula 2. Estats Units: taxa de beneficis (r), participació dels beneficis empresarials no financers en excedent brut d'explotació $(\alpha)$, participació d'excedent brut d'explotació en la renda nacional (q) i productivitat del capital( $\pi \mathrm{k})$

\begin{tabular}{|c|c|c|c|c|c|c|c|c|c|c|}
\hline & & & & & & \multicolumn{5}{|c|}{ Factors de greixements } \\
\hline & 1946 & 1968 & 1980 & 2000 & 2013 & 1946-1968 & 1968-1980 & \begin{tabular}{|l|}
$1980-2000$ \\
\end{tabular} & \begin{tabular}{|l|}
$2000-2013$ \\
\end{tabular} & 1946-2013 \\
\hline 1 Beneficis empreses no financeres & 16,0 & 88,1 & 171,8 & 499,1 & 1246,3 & 5,5063 & 1,9501 & 2,9051 & 2,4971 & 77,8938 \\
\hline $2 K_{t-1}$ & 133,6 & 631,4 & 2409,3 & 7569,6 & 13766,7 & 4,7260 & 3,8158 & 3,1418 & 1,8187 & 103,0442 \\
\hline \begin{tabular}{l|l}
$\mathbf{r}(1 / 2)$ \\
\end{tabular} & 0,1198 & 0,1395 & 0,0713 & 0,0659 & 0,0905 & 1,1651 & 0,5110 & 0,9247 & 1,3730 & 0,7559 \\
\hline 4 Excedent Brut d'Explotació (EBE) & 84,4 & 340,2 & 964,5 & 3735,9 & 6926,2 & 4,0308 & 2,8351 & 3,8734 & 1,8540 & 82,0640 \\
\hline $5 \times(1 / 4)$ & 0,1896 & 0,2590 & $0, \mathbf{1 7 8 1}$ & 0,1336 & 0,1799 & 1,3660 & 0,6878 & 0,7500 & 1,3469 & 0,9492 \\
\hline 6 Quota d'Excedents (q) & 0,4189 & 0,4088 & 0,3974 & 0,4194 & 0,4751 & 0,9761 & 0,9721 & 1,0553 & 1,1328 & 1,1344 \\
\hline $\left.7 \times 15^{*} 6\right)$ & 0,0794 & 0,1059 & 0,0708 & 0,0560 & 0,0855 & 1,3334 & 0,6686 & 0,7915 & 1,5258 & 1,076 \\
\hline 8 Productivitat del Capital - $\pi_{k}(3 / 7)$ & 1,5082 & 1,3179 & 1,0073 & 1,176 & 1,0589 & 0,8738 & 0,7643 & 1,1682 & 0,8999 & 0,7021 \\
\hline $9 \mathrm{r}=\alpha \mathrm{aq} \times \mathrm{nk}$ & 0,1198 & 0,1395 & 0,0713 & 0,0659 & 0,0905 & 1,1651 & 0,5110 & 0,9247 & 1,3730 & 0,7559 \\
\hline
\end{tabular}

Font: elaboració pròpia

Es detecten els següents fets:

1. La major recuperació de (r) es produeix entre 1946 i 1968, quan la (q) es manté dins del rang d'equilibri $\left(q^{*}\right)$ i quan el factor de creixement de $(r)$ va ser d'1,17, gràcies exclusivament al factor de financiarització $(\alpha)$ amb un 1,37: són anys de fortes inversions en el sector industrial, amb un creixement en els guanys de les empreses no financeres amb un factor de 5,5. Mentrestant, la quota d'excedents (q) i la productivitat del capital ( $\pi \mathrm{k}$ ) cauen lleugerament, amb els factors de 0,98 i 0,87 respectivament.

24 Shaikh 1990. 
2. Les crisis dels 1970 (1968-1980), quan la (q) se situa per sota de la forquilla d'equilibri $\left(\mathrm{q}^{*}\right)$, i es subratlla una forta disminució de la taxa de benefici $(\mathrm{r})$ que aconsegueix valors a l'entorn de la meitat de l'aconseguit durant la fase final de la regulació keynesiana, amb un factor de 0,51. Aquesta disminució s'explica per la forta caiguda de la taxa del factor de financiarització $(\alpha)$ a 0,69 (la qual cosa infereix crisi industrial) i de la productivitat del capital $(\pi \mathrm{k})$, amb un factor de 0,76 ; a l'ensems, la quota d'excedents (q) es va reduir lleugerament durant el mateix període en un factor de 0,97. La característica principal d'aquesta primera fase de la financiarització de l'economia va ser el creixement dels interessos nets i els pagaments diversos amb un factor de 6,75 i dels beneficis financers amb un factor de 3,85.

3. El període neoliberal (1980-2013) es pot dividir en dos sub-períodes: 1980 a 2000, quan la quota d'excedents $(q)$ es troba dins de la forquilla d'equilibri $\left(q^{*}\right)$; i des de 2000 fins a 2013, quan (q) se surt de $\left(q^{*}\right)$ a partir de l'any 2000, tot recollint les diverses crisis financeres de les dot.com des de la primavera d'aquell any i de les subprime, que fou arran del tercer trimestre de 2007. Al començament del primer d'aquests dos sub-períodes (1980-2000), el descens de la taxa de benefici (r) s'ubica entorn d'un 7\%, a causa dels canvis en el comportament de les seves variables explicatives en comparació als seus valors durant la crisi de 1970. La quota d'excedents (q) tenia un factor de creixement d' 1,05 (amb un factor del 2,41 pel salari i del 2,50 per a la productivitat del treball i, per tant, és el primer període en el què el salari creix menys que la productivitat), a causa del canvi neoliberal al mercat laboral; la productivitat del capital ( $\pi \mathrm{k}$ ), un factor d' 1,16; i la financiarització (a) de l'economia un factor de 0,75. Durant aquest període, les principals característiques de la financiarització de l'economia van ser:

- Creixement de la renda d'interessos nets i pagaments diversos en un factor de 9,53 (com a conseqüència de l'auge de les inversions borsàries de les empreses punto.com);

- Creixement dels ingressos de la propietat en un factor de 4,42 (indicador de l'inici del boom immobiliari a partir de la segona meitat dels anys 1990);

- Creixement dels guanys financers per un factor de 4,73 (com a conseqüència de l'auge de les inversions borsàries de les empreses punto.com i del boom immobiliari).

Hi ha un contrast notable en el comportament de les variables explicatives per a la taxa de benefici ( $\mathrm{r}$ ) en els dos períodes en els quals la quota d'excedents (q) està en el rang de la forquilla d'equilibri $\left(\mathrm{q}^{*}\right)$, com és el cas entre la fase de regulació keynesiana (1946-1968) i la neoliberal (1980-2000).

Les principals diferències són:

- Els canvis en el comportament del factor de financiarización $(\alpha)$, que tenia taxes de creixement per sobre de l'1 durant el període de forta inversió en la indústria des de 1946 fins a 1968 i per sota d'l entre 1980 i 2000, després de la gran crisi industrial de la dècada de 1970, accentuat per la creixent financiarització de l'economia entre 1968 i 1980; 
- El caràcter excepcional de la recuperació de la productivitat del capital $(\pi \mathrm{k})$ entre 1980 i 2000, impulsat per la revolució de les TIC i el creixement de la productivitat en els serveis (bàsicament, en el comerç, en empreses immobiliàries i en empreses financeres, sobretot a partir de la segona meitat dels 1990); $; 2$

- La represa de la quota d'excedents (q) com a conseqüència de l'objectiu per recuperar-se de la crisi de 1970 gràcies a la regresivitat fiscal en l'IRPF i l'impost sobre beneficis, les reformes laborals i la desregulació dels mercats, tant a nivell nacional com internacional. Es tracta, en definitiva, d'un renovat control sobre els costos de producció, especialment els salarials, amb un resultat: els salaris van créixer més lentament que la productivitat del treball.

En el subperíode 2000-2013, caracteritzat per crisis financeres recurrents i per la Gran Recessió, no es dóna una caiguda disruptiva de la taxa de guany com sí que es va produir al llarg de la crisi dels anys 1970, ja que en aquesta etapa la taxa de guany (r) no només es va recuperar, sinó que presenta el seu màxim creixement per a tot el període analitzat amb un factor l'1,37. Tal comportament clarament expansiu de la taxa de guany es sustenta, per un costat, amb una creixent desigualtat social, ja que la quota d'excedents (q) accentua el seu avanç amb un factor 1,13 (amb 1,43 pel salari i 1,58 per a la productivitat del treball), i representa el seu valor màxim pel conjunt del període analitzat. Alhora, el factor de financiarització torna a recuperar un creixement positiu d'1,35, comparable al que va registrar al llarg de la fase keynesiana, gràcies a que els beneficis de les empreses no financeres $(\mathrm{P})$ es tornen a comportar millor que els de les empreses financeres amb factors de creixement del 2,50 i 2,02 respectivament. Però, a diferencia de la fase keynesiana, en aquesta la productividad del capital $\left(\pi_{\mathrm{K}}\right)$ torna a decréixer retornant a la seva tendència històrica, amb un factor de 0,90 .

El gràfic 3 és revelador referent a això i reuneix l'essència de l'exposat fins ara. Hom mostra les quatre variables de referència, en tendència, per al període 19462013. La variable clau és la taxa de benefici (r), que presenta un comportament estable des de l'inici de la sèrie fins a finals dels anys seixanta; moment a partir del qual comença una caiguda substancial que s'estabilitza després de 1980, per mantenir-se més o menys estable fins a la Gran Recessió i, a partir de 2010, manifestar una altra senda de certa recuperació. Si s'observa amb detall el comportament de la taxa de benefici des de 1968 a 1980, s'aprecia que la tendència negativa cada vegada és menys accentuada ja que ve compensada amb un major pendent positiu de la quota d'excedent, que se contraposa als efectes negatius que exerceixen la productivitat del capital i el factor de financiarització. A partir de 1980, la taxa de benefici entra en un període d'estabilitat en el context de la regulació neoliberal. Això s'explica per la confluència de dos efectes, un positiu i negatiu. Ambdós actuen a tall de tendència i contra-tendència, amb el resultat de l'estabilització de la taxa de benefici:

25 Navinés 2006. En aquest treball es pren l'economia dels Estats Units com a referència del canvi de model de terciarització provocat per la cinquena revolució tecnològica. 


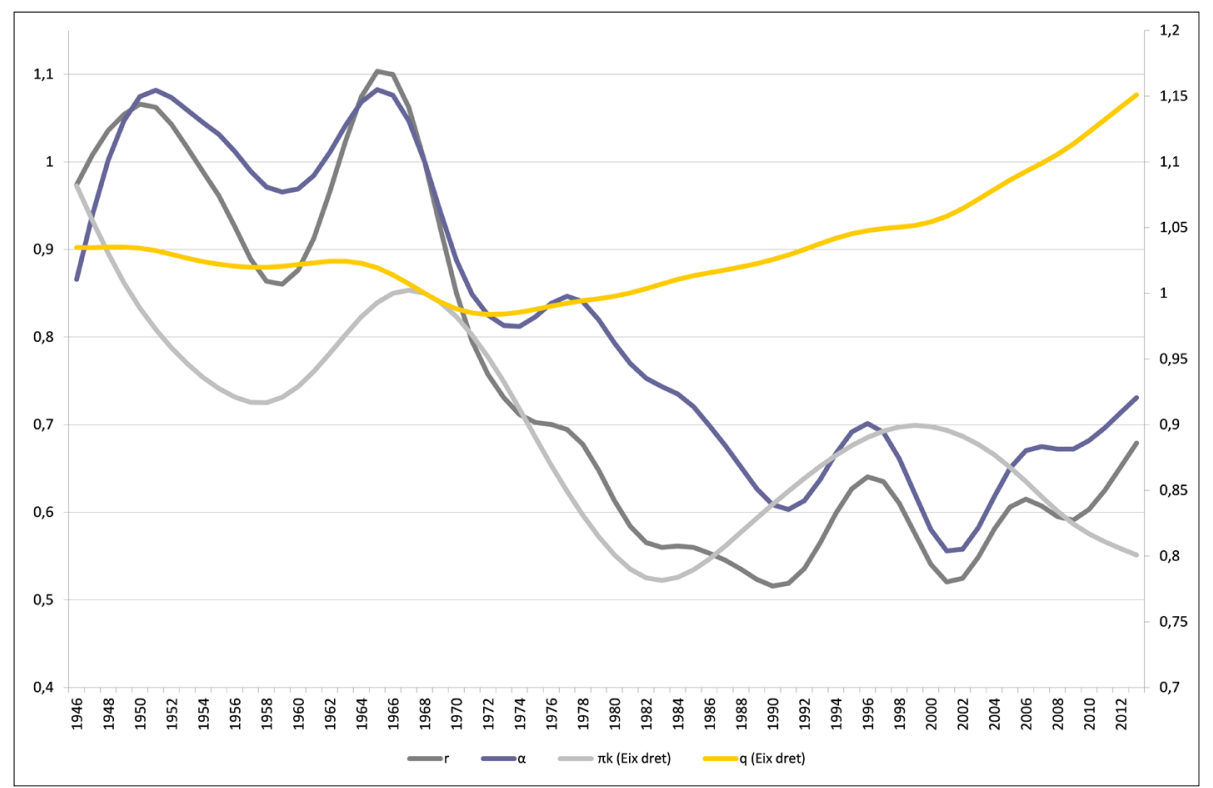

Gràfic 3.

Font: Elaboració pròpia

- Tendències negatives: la productivitat del capital, malgrat un repunt a mitjan dels 1990 per l'efecte de les empreses punto.com; el factor de financiarització, si bé és cert que en aquest cas, hom albira una represa al llarg del primer decenni del segle XXI per mor de les crisis financeres dels dot.com i subprime.

- Tendències positives: exclusivament, la quota d'excedent va creixent, alhora que augmenta la desigualtat social.

En definitiva, la caiguda de la taxa de benefici, que venia esdevenint-se des de finals dels seixanta, s'aconsegueix detenir i estabilitzar mitjançant el creixement de la desigualtat i de la participació de les rendes del capital en la renda nacional, mesurada per (q). Això pot compensar una caiguda de la productivitat del capital i d'una economia cada vegada més depenent de la dinàmica financera, mesurada pel factor de financiarització a partir de desviar cada vegada més part de la riquesa nacional cap a les rendes de capital financer amb el desplaçament de recursos de l'economia productiva. Tal evolució perjudica la sostenibilitat de les inversions productives i afebleix els efectes spillover d'aquestes inversions, que són els que incorporen innovacions continues en els processos productius. I que, al seu torn, mantenen el creixement de la productivitat del capital al llarg del temps.

Per aprofundir en aquest tema, és important l'anàlisi de la Tendència a la Igualació de la Taxa de Guany (TITG). El factor de financiarització $(\alpha)$ de l'economia ens indica també la participació de la taxa de guany de les empreses no financeres ( $\mathrm{r}$ ) en la taxa de guany total de l'economia (r), és a dir: $\mathrm{r} / \mathrm{rtotal}=(\alpha)$, de tal manera que una disminució del valor de $(\alpha)$ també indica una disminució de les oportunitats de negoci rendibles en l'esfera real respecte a l'esfera financera, i per la TITG, una transferència d'excedents des de l'economia productiva cap a l'economia financera i a l'inrevés. En el cas dels EUA els valors inicials i finals de $(\alpha)$ (en valors tendència) per a cada període analitzat és el següent: 

( $\alpha$ ) inicial
( $\alpha$ ) final
$\operatorname{TITG}(*)$

$\begin{array}{llll}1946-1968 & 21,3 \% & 24,6 \% & \text { Efecte }(+) \\ 1968-1980 & 24,6 \% & 19,5 \% & \text { Efecte }(-) \\ 1980-2000 & 19,5 \% & 14,3 \% & \text { Efecte }(-) \\ 2000-2013 & 14,3 \% & 18,0 \% & \text { Efecte }(+)\end{array}$

Addenda:

$\begin{array}{llll}2000-2007 \text { (crisi dot.com) } & 14,3 \% & 16,6 \% & \text { Efecte }(+) \\ 2007-2013 \text { (Gran Recessió) } & 16,6 \% & 18,0 \% & \text { Efecte }(+)\end{array}$

(*) Efecte (+) indica més oportunitats de negoci rendibles en l'economia productiva que en l'economia financera, ja que la seva rendibilitat creix més ràpid; i Efecte (-) indica l'inrevés.

Tal com mostra el quadre anterior, la sostenibilitat del procés inversor productiu només s'ha produït al llarg del període keynesià i a partir de 2000. Això s'explica per les crisis monetàries de les dot.com (primavera de 2000), que per evitar els seus efectes negatius sobre el sector real van donar lloc a la baixada dels tipus d'interès. La conseqüència fou alimentar la crisi de les subprime a partir de 2007 i l'esclat de la Gran Recessió des de setembre de 2008 amb la fallida de Lehman Brothers i la crisi del sistema financer internacional.

\section{Recapitulacions i reflexions finals}

El treball ha pretès indicar que conceptes bàsics de l'economia clàssica són de gran utilitat per a entendre les crisis econòmiques i, de forma particular, la Gran Recessió. En aquest respecte, un element esdevé determinant: el temps històric, factor que massa sovint no apareix amb la nitidesa que pertoca en els models més convencionals de l'economia acadèmica. L'errada, al nostre entendre, consisteix en una gran part en desentendre's de l'experiència històrica i perdre de vista una visió realista de la realitat econòmica i social que ens envolta. Aquesta visió més realista és més pròpia dels economistes keynesians i de l'economia heterodoxa -ecològica, social-, i es troba confrontada a una visió més pròpia del pensament dominant en l'Acadèmia. Aquest és, per exemple, el que ha adoptat l'Eurozona a l'hora d'aplicar una política d'austeritat, on es segueixen de forma autista les directrius d'un manual d'economia simplista, on només hi consta una política monetària restrictiva i es prioritza la lluita contra la inflació i una política fiscal basada en l'equilibri pressupostari, sense atendre a l'objectiu del creixement econòmic i la plena ocupació. I on el problema sobre el creixement de les desigualtats socials ni tan sols entra com un dels temes centrals del receptari. És així com: 
a) Es nega el conflicte distributiu entre treball i capital, que es manifesta amb la determinació del salari d'equilibri en el mercat de treball.

b) Es nega l'existència de crisis econòmiques sistèmiques, en tant i en quant hom argüeix que hi ha preus d'equilibri i l'autoregulació dels mercats.

c) Es nega la necessitat de què l'Estat intervingui a través de la política fiscal i de les inversions públiques, com la manera més idònia per a poder sortir de la crisi.

Les propostes que emanen d'aquest triple eix, enfocades a la política econòmica, són més aviat un parany ideològic disfressat de ciència.

L'Economia Política, la que en concret emana dels pensadors clàssics, aporta al nostre entendre una visió realista sobre la dinàmica econòmica i la societat. La seva adscripció a períodes posteriors és il-lustrativa d'una forma determinada d'entendre els processos econòmics: l'accent no es posa sobre l'existència o no de l'equilibri de Menger i de l'òptim de Pareto, sinó en poder bastir quins són els principals problemes i contradiccions que es generen en el temps històric en el què es desenvolupa el món real. El centre de l'anàlisi econòmica es focalitza en el conflicte distributiu entre treball i capital, i en entendre que el creixement econòmic i el benestar social depenen de com es resolgui aquesta pugna distributiva, ja que l'anàlisi econòmica ens ha de permetre copsar com funciona una economia basada en la divisió del treball, representada com un procés circular de producció i consum. I de quina manera les condicions tècniques de producció i les socials de distribució de la renda determinen el seu funcionament al llarg -un cop més-del temps històric. Heus ací, de bell nou, el nus gordià: la trajectòria històrica, la Història Econòmica. La cadena seqüencial bàsica d'aquest plantejament és la següent, deliberadament sintètica: la variació de la distribució de la renda, mesurada per la participació dels salaris en la renda nacional $(\mathrm{W} / \mathrm{Y})$ determina la participació dels beneficis en la renda nacional (B/Y) i l'evolució de la taxa de guany ( $\mathrm{r}$ ), la qual infereix alhora el comportament de les inversions productives (I), i aquestes el creixement de la renda (Y). Podria ser aquest un petit resum de l'economia clàssica -que ha servit com a base del present treball- que hom pot representar esquemàticament així:

\section{Variació $(\mathrm{W} / \mathrm{Y}) \rightarrow$ Variació $(\mathrm{B} / \mathrm{Y}) \rightarrow$ Variació $(\mathrm{r}) \rightarrow$ Variació $(\mathrm{I}) \rightarrow$ Variació $(\mathrm{Y})$}

L'observació històrica ens permet contrastar aquesta hipòtesi de treball de l'Economia Política a partir de la recerca pròpia sobre l'economia d'Estats Units -a partir de dades de caire macroeconòmic, de comptabilitat nacional-.

En aquest respecte, a les investigacions que donen cobertura a aquest assaig teòric:

- Hem puntualitzat els rendiments decreixents com una noció que hem fet extensiva a les economies industrials i de serveis, de forma que les ombres de Ricardo i Marx es projecten en aquesta idea.

- Ens hem centrat en la visió de la crisi actual com de sobreacumulació i subconsum, en el sentit d'una manca de formació de capital en l'esfera produc- 
tiva. La relació amb els canvis tecnològics i les innovacions és determinant, sempre en el cas de que es produeixin aquestes transformacions en la fase baixista de la recessió. Aquí, la influència de Marx i Schumpeter és rellevant. La manera com evoluciona la taxa de benefici constitueix una línia explicativa de gran força per comprendre la naturalesa i composició de les crisis. En aquest respecte, les aportacions de Shaikh i Astarita han resultat aclaridores.

- No obstant això, pensem que hom albira un domini aclaparador del capital financer sobre el capital productiu, en el sentit de que mentre aquest darrer palesa tendències evidents a una caiguda en la seva taxa de benefici, el primer assoleix una dimensió important en el procés d'acumulació de capital, de forma que en l'agregat de guanys del capital en la seva totalitat (K), la part del lleó correspon a aquest capital financer. Marx, Schumpeter, Keynes i els economistes neokeynesians i neoschumpeterians Sylos Labini, Minsky i Pérez constitueixen en aquest respecte senyes d'identitat irrenunciables.

Presentem a continuació un quadre resum de l'anàlisi aplicada sobre l'economia dels Estats Units pel període 1946-2013:

\begin{tabular}{lccccccc}
\hline Períodes & \multicolumn{2}{c}{ Forq. d'equilibri } & $\mathrm{g}($ PIB real $)$ & $\mathrm{r}$ & $\pi \mathrm{k}$ & $\mathrm{q}$ \\
& & & & & & & \\
\hline $1946-68(\mathrm{~K})$ & Sí $\left(\mathrm{q}=\mathrm{q}^{*}\right)$ & 3,89 & 1,16 & 0,87 & 0,97 & 1,36 & Ef. $(+)$ \\
$1968-80(\mathrm{C} 70)$ & No $\left(\mathrm{q}<\mathrm{q}^{*}\right)$ & 2,57 & 0,51 & 0,76 & 0,97 & 0,68 & Ef. $(-)$ \\
$1980-00(\mathrm{NL})$ & Sí $\left(\mathrm{q}=\mathrm{q}^{*}\right)$ & 3,51 & 0,92 & 1,16 & 1,05 & 0,75 & Ef. $(-)$ \\
$2000-13(\mathrm{GR})$ & No $\left(\mathrm{q}>\mathrm{q}^{*}\right)$ & 1,77 & 1,37 & 0,89 & 1,13 & 1,34 & Ef. $(+)$
\end{tabular}

K: Període keynesià. C70: Crisi dels 1970. NL: Període neoliberal. GR: Gran Recessió. Ef.: Efecte.

A tall de fets estilitzats podem concloure:

1) S'ha comprovat que els màxims creixements del PIB real s'obtenen quan es dóna la forquilla d'equilibri en la distribució funcional de la renda, és a dir, quan els valors de (q) entren dins la forquilla d'equilibri $\left(q^{*}\right)$, que en el cas dels Estats Units $s^{\prime}$ ha estimat que varia entre un $40,88 \%$ i un $42,93 \%$. En aquest cas, es troben el període keynesià (1946-1968) i el neoliberal (1980-2000), amb creixements reals del PIB del 3,89\% i el 3,51\% anual acumulatiu.

2) Fora d'aquests "períodes d'equilibri" hom aprecia dues crisis de regulació: la dels anys 1970 (1968-1980), que s'ha denominat com a crisi de costos de producció, que es produeix quan $\left(\mathrm{q}<\mathrm{q}^{*}\right)$ i en la què el creixement real del PIB va ser del 2,57\%; i la crisi actual (2000-2013) que hem caracteritzat com a crisi de demanda, quan (q 
$>\mathrm{q}^{*}$ ), i on el creixement real del PIB va registrar el mínim de tot el període analitzat amb un $1,77 \%$.

3) De los dues crisis de regulació, podem constatar que només la dels anys 1970 ha provocat una caiguda disruptiva de la taxa de guany, ja que aquests valors es varen situar al final de la crisi (1980) a la meitat dels seus valors inicials (1968), car la taxa de guany al llarg d'aquest període de crisi (1968-1980) va caure amb un factor del creixement del 0,51, creant la necessitat de canviar del mode de regulació keynesià al neoliberal gràcies a la cinquena revolució tecnològica de les TIC i als canvis institucionals. Però, a la crisi actual (2000-2013), contràriament la taxa de guany no només no ha caigut sinó que ha augmentat amb un factor de creixement del 1,37. Per tant, malgrat la crisi, no es visualitza que la regulació neoliberal, en termes del comportament de la taxa de guany, tingui necessitat de transitar envers un nou mode de regulació.

4) Hem constatat el desacoblament que s'ha produït entre el creixement del PIB real i el creixement de la taxa de guany al passar de la regulació keynesiana a la neoliberal. La recuperació del creixement del PIB real en la fase neoliberal (1980-2000) no es correspon amb una del creixement de la taxa de guany, ja que aquesta continua disminuint amb un factor del 0,92; i la crisi actual (2000-2013), que presenta el menor creixement del PIB de tot el període analitzat, no es veu acompanyada per una caiguda de la taxa de guany, sinó tot el contrari, ja que experimenta el seu creixement màxim amb un factor 1,37.

5) Aquest desacoblament que s'ha produït entre el creixement del PIB real i el creixement de la taxa de guany, creiem que té a veure amb la desindustrialització que s'ha produïda a partir de 1968, que es correspon amb un intens procés de terciarització de l'economia dels Estats Units, bàsicament promogut per les activitats comercials, de promoció immobiliària i especialment dels serveis financers. Aquest efecte queda recollit per la variable factor de financiarització $(\alpha)$ i per la TITG, de tal manera que quan aquesta augmenta de valor, ens indica que el pes dels excedents de les empreses no financeres de l'economia creix més ràpid que els de les empreses financeres, i alhora s'incrementen també les oportunitats de negoci rendibles en aquestes empreses productives en relació a les financeres. I, per tant, és dóna un efecte (+) via la TITG en l'assignació de nou finançament cap a l'economia productiva en relació a les assignacions cap a l'economia financera en activitats especulatives. Això vol dir que, en termes del multiplicador de la inversió productiva, aquest efecte va ser màxim al llarg del període keynesià, amb valors per sobre del $25 \%$ (essent 1968 el darrer any on s'obté un guarisme superior al 25\%), mentre que en el període neoliberal aquest indicador ha caigut per sota del $20 \%$, assolint un mínim el 2001 del $10 \%$ al final del període, tot i que $(\alpha)$ presenta un factor de creixement d'1,34 i que només arriba el 2013 a un valor de $(\alpha)$ del 17,17\%; és a dir, al 66\% del que aquesta variable presentava al final de l'etapa keynesiana.

6) Com a variables explicatives del comportament de la taxa de guany hem identificat com a tendència principal el comportament de la productivitat del capi- 
tal $(\pi \mathrm{k})$, que presenta una orientació decreixent al llarg de tot el període analitzat, excepte a la fase neoliberal (1980-2000), gràcies al xoc que es produeix amb la irrupció de la revolució tecnològica de les TIC sobretot en els serveis, i amb una intensitat especial al llarg de la dècada dels anys 1990. La contratendència principal per recuperar o mantenir la taxa de guany en el període keynesià va ser augmentar la $(\alpha)$ gràcies al manteniment en bona part del període (1946-1968) del procés inversor en el sector manufacturer dels béns de consum de masses; mentre a partir de 1980 la contratendència principal ha estat l'augment de la desigualtat mesurada a partir del factor de creixement de (q), que ha estat sempre positiu i creixent, a diferència d'allò que passava abans de 1980, en què es va mantenir amb taxes decreixents a l'entorn d'un factor del 0,97.

7) La sortida de la crisi actual, d'acord amb l'anàlisi plantejat, exigiria com a condició necessària i suficient el retorn de la desigualtat mesurada per $(q)$ als nivells del $40 \%$ al $43 \%$ que són els que es corresponen amb la forquilla d'equilibri (q*), i no del 47,5\% en els que està situat el 2013, darrer any de la sèrie i valor màxim de la mateixa. La disminució de la desigualtat efectivament pot representar una tendència a la baixa de la taxa de guany, però també és cert que la seva minva tindria un efecte positiu sobre la demanda agregada via major consum salarial. I això podria millorar els nivells d'utilització dels equips productius de les empreses no financeres, permetent beneficiar els registres de la productivitat del capital ( $\pi \mathrm{k})$, alhora que s'hauria de continuar mantenint les taxes positives de creixement del factor de financiarització $(\alpha)$.

\section{Bibliografia}

ATKINSON, Anthony B.; PIKETTY, Thomas; SAEZ, Emmanuel. Top incomes in the long run of history. Journal of economic literature, 201 1, vol. 49, no 1, p. 3-71.

AUSTIN, G. et alter, Labour-Intensive Industrialization in Global History. Londres-Nova York, 2013.

BECATTINI, Giancomo, BIANCHI, Giuliano. Analisi dello sviluppo multiregionale vs. analisi multiregionale dello sviluppo. In BIANCHI, G.- MAGNANI, I. (Eds.). Sviluppo multiregionale: teorie, metodi, problemi. Milà: Franco Angeli, 1985.

BELLETINI; Giorgio, DELBONO, Flabio. Persistence of high income inequality and banking crises. Quaderni-Working Paper DSE, 885, 2013.

BLANCHARD, Olivier. Adjustment within the euro. The difficult case of Portugal, http:// economics.mit.edu/files/740, 2006.

BLANCHARD, Olivier. et alter. In the Wake of the Crisis. Cambridge-Londres: The MIT Press, 2012.

BLANCHARD, Olivier, LEIGH, Daniel. «Growth Forecast Errors and Fiscal Multipliers», FMI, working paper 13/1, 2013. http://www.imf.org/external/pubs/ft/ wp/2013/wpl301.pdf, 
BLANCHARD, Olivier, CERUTTI, Eugenio; SUMMERS, Lawrence. et alter, Comment on "Inflation and Activity", Laurence Ball, agost de 2015. http://www.econ2.jhu.edu/ People/Ball/BlanchardComment.pdf.

BRANDT, Loren, RAWSKI, Thomas. China's Great Transformation. Cambridge: Cambridge University Press, 2008.

BRENNER, Robert. La economía de la turbulencia global. Barcelona: Akal, 2009.

BRENNER, Robert. La expansión económica y la burbuja bursátil. Madrid: Akal, 2003.

BRICALL, Josep Maria. Cinco ensayos sobre la crisis y sus consecuencias para el estado de bienestar. Barcelona: RBA Libros, 2013.

BRICALL, Josep Maria. Actualidad de G. D. De Bernis. 2013, inèdit.

CASTELLS, Manuel. La era de la información. Madrid: Alianza, 2000.

COOPER, George. The Origin of Financial Crises. Londres: Harriman House, 2008.

CRAFTS, Nicholas, FEARON, Peter. The Great Depression of the 1930s. Lessons for Today. Oxford, Oxford University Press, 2013.

DE BERNIS Gérard. El capitalismo contemporáneo. Mèxic: Nuestro Tiempo, 1988.

DE GRAUWE, P. «Governance of a Fragile Eurozone», Economic Policy, CEPS working documents, http://www.ceps.eu/book/governance-fragile-eurozone, 2011.

EICHENGREEN, Barry. Globalizing Capital: a history of the International Monetary System. Nova Jersei, Princeton University Press, 1998.

FATÁS, A., SUMMERS, L. «The permanent Effects of Fiscal Consolidations», INSEAD, ABFER i CEPR, 2015.

FISHER, Irvin. The Debt-Deflation Theory of Great Depressions. Econometrica, 1933.

FLASSBECK, Heiner et alter. ¡Actúen ya! Un manifiesto global para recuperar nuestras economías y salir de la crisis. Barcelona, Deusto, 2013.

FMI (Fons Monetari Internacional).

https://www.imf.org/external/pubs/ft/sdn/2015/sdn1503.pdf.

FOLEY, Duncan. The Political economy of post-crisis global capitalism, Universidat de Chicago, 2010. https://sites.google.com/a/newschool.edu/duncan-foley-homepage/home/downloads

GARNAUT, Ross, SONG, Ligang. China: New Engine of World Growth. ANU Press, 2012. GARNAUT, Ross, SONG, Ligang, GOLLEY, Jane. China:The Next Twenty Years of Reform and Development, ANU Press, 2010.

GORDON, D., EDWARDS, R., REICH, M. Trabajo segmentado, trabajadores dividides. Madrid, Ministerio de Trabajo y Seguridad Social, 1986.

HARVEY, David. Diecisiete contradicciones y el fin del capitalismo. Madrid: Traficantes de Sueños, 2014.

HUDSON, Michael. Finance Capitalism and its Discontents. Interviews and speeches, 2003-2012. Dresden: ISLET, 2012.

KATZ, Claudio. La economía marxista hoy. Seis debates teóricos. Madrid: Maia Ediciones, 2010. 
KEEN, Steve. Finance and economic breakdown: modelling Minsky's Financial Instability Hypothesis. Journal of Post Keynesian Economics, 1995, vol. 17, 4, p. 607635.

KEEN, Steve. La economía desenmascarada. Madrid: Capitan Swing, 2013.

KRUGMAN, Paul. El gran engaño. Barcelona: Crítica, 2004.

KRUGMAN, Paul. El internacionalismo "moderno". La economía internacional y las mentiras de la competitividad. Barcelona: Crítica, 1997.

KRUGMAN, Paul. Fast Growth and Stable Prices: Just Say No. Economist, agost, 1996. LAPAVITSAS, Costas. Crisis en la Eurozona. Madrid: Capitan Swing, 2013.

LAPAVITSAS, Costas. El capitalismo financiarizado: expansión y crisis. Madrid: Maia Ediciones, 2009.

LAPAVITSAS, Costas. Profiting without Producing. Londres-Nova York, 2013.

LAPAVITSAS, Costas., FLASSBECK, Heiner. Contra la troika: crisis y austeridad en la Eurozona. Madrid: Akal, 2015.

MADRICK, Jeff. Computers: waiting for the revolution. New York Review of Books, març, 1998.

MADRICK, Jeff. Seven Bad Ideas. Nova York: Alfred Knopf, 2014.

MANERA, Carles. La extensión de la desigualdad. Austeridad y estancamiento. Madrid: La Catarata, 2015.

MANERA, Carles, NAVINÉS, Ferran, FRANCONETTI, Javier. Income distribution, profit and inequality: their role in US economic history, 1910-2010. Économies et Sociétés, 50, 6/2015,877-903.

MARGLIN, Sthephen, SCHOR, Juliet. The Golden Age of Capitalism. Nova York: Clarendon Press, 1990.

MARX, Karl. El capital (llibre primer). Mèxic: Siglo XXI, 2010.

MARX, Karl. Teorías sobre la plusvalia. Mèxic: FCE, 1980.

MILANOVIC, Branko. Global Income Inequality: What It Is And Why It Matters?, DESA Working Paper 26, 2006.

MINQI, Li. "Capitalism with zero profit rate? Limits to growth and he law of the tendency for the fate of profit to fall», working paper, University of Utah, núm. 200705, www.econstor.eu/dspace/bitstream/10419/64451/1/572640692.pdf.

MINSKY, Hayman. John Maynard Keynes. Nova York: McGraw Hill Professional, 2008.

MINSKY, Hayman. Stabilizing an Unstable Economy. Nova York: McGraw Hill Professional, 2008.

NAVINÉS, Ferran. Algunes reflexions fetes des de l'enfocament clàssic de l'excedent sobre el procés de terciarització i especialització productiva: el cas de Balears. In FORCADES, A. Repensem el model de creixement balear. Palma: Cambra de Comerç de Mallorca, Eivissa i Formentera i Cercle d'Economia de Mallorca, 2006. PÉREZ, Carlota. Revoluciones Tecnológicas y Capital Financiero: La dinámica de las burbujas financieras y las épocas de bonanza. Mèxic: Siglo XXI, 2004.

PIKETTY, Thomas. L'economia de les desigualtats. Barcelona: Edicions 62, 2014.

PIKETTY, Thomas. Le capital au XXIème siècle. París: Seuil, 2013. 
PIORE, M., SABEL, C. La segunda ruptura industrial. Madrid: Alianza, 1990;

REINHART, Ms Carmen; ROGOFF, Mr Kenneth. Financial and sovereign debt crises: some lessons learned and those forgotten. International Monetary Fund, 2013. https://www.imf.org/external/pubs/ft/wp/2013/wp13266.pdf.

RICARDO, David. Principios de Economía Politica y Tributación. Madrid: Pirámide, 2003.

RONCAGLIA, Alessandro. Elements fonamentals d'economia politica. Vic: Eumo Editorial, editorial, 1994.

SCHUI, Florian. Austerity. The Great Failure. New Haven-Londres: Yale University Press, 2014.

SCHUMPETER, Joseph A. Ciclos económicos: análisis teórico y estadístico del proceso capitalista. Saragossa: Universidad de Zaragoza, 2002.

SCHUMPETER, Joseph A. Historia del análisis económico. Barcelona: Ariel, 2012.

SHAIKH, Anuar. The first great depression of the 21 st century. Socialist Register, vol. $47,47$.

SHAIKH, Anuar. Valor, acumulación y crisis. Bogotá: Tercer Mundo Editores, 1990.

STIGLITZ, Joseph. El malestar en la globalización. Madrid: Taurus, 2002.

STIGLITZ, Joseph. Los felices 90. La semilla de la destrucción. Madrid: Taurus, 2003.

SYLOS LABINI, Paolo. Las fuerzas del desarrollo y del declive. Vilassar de Mar: Oikos-tau, 1988.

TAPIA, Jose Antonio, ASTARITA, Rolando. La Gran Recesión y el capitalismo del siglo XXI. Madrid: Catarata, 2011.

VAROUFAKIS, Yanis; HOLLAND, Stuart; GALBRAITH, James K. A modest proposal for resolving the eurozone crisis. Notas Económicas, 2015, no 41, p. 7-15. http:// varoufakis.files.wordpress.com/2013/07/a-modest-proposal-for-resolving-theeurozone-crisis-version-4-0-finall.pdf

ZILIAK, Steve., McCLOSKEY, Deirdre. The Cult of Statistical Significance: How the Standard Error Costs Us Jobs, Justice, and Lives. Michigan: University of Michigan Press, 2008.

(c) Copyright: Carles Manera, Ferran Navinés, Javier Franconetti, José Pérez Mpntiel, 2019

(c) Copyright: Scripta Nova, 2019

Fitxa bibliogràfica:

MANERA, Carles; NAVINÉS, Ferran; FRANCONETTI, Javier; PÉREZ MONTIEL, José. Crisi, desigualtat i anàlisi econòmica, 1910-2015: alguns instrumenbts de l'economia clàssica. Scripta Nova. Revista Electrónica de Geografía y Ciencias Sociales. Barcelona: Universidad de Barcelona, 15 de març de 2019, vol. XXII, nº 601[ISSN: 1138-9788] 